\title{
Compressive testing and numerical modelling of concrete-filled double skin CHS with austenitic stainless steel outer tubes
}

\author{
Fangying Wang ${ }^{\mathrm{a}}$, Ben Young ${ }^{\mathrm{b}}$, Leroy Gardner ${ }^{\mathrm{c}}$
}

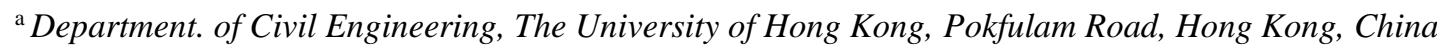

${ }^{\mathrm{b}}$ Department of Civil and Environmental Engineering, The Hong Kong Polytechnic University, Hong Kong, China.(Formerly, Department of Civil Engineering, The University of Hong Kong, Pokfulam Road, Hong Kong, China.)

${ }^{\mathrm{c}}$ Department of Civil and Environmental Engineering, Imperial College London, London, UK

*corresponding author. Tel.: +852 54877715 .

E-mail address: christine.wang@ @onnect.hku.hk

\begin{abstract}
A comprehensive experimental and numerical study of concrete-filled double skin tubular (CFDST) stub columns is presented in this paper. A total of 23 tests was carried out on CFDST specimens with austenitic stainless steel circular hollow section (CHS) outer tubes, high strength steel CHS inner tubes, and three different grades of concrete infill (C40, C80 and C120). The ultimate load, load-deflection histories and failure modes of the stub columns are reported. The test results were employed in a parallel numerical simulation programme for the validation of the finite element $(\mathrm{FE})$ model, by means of which an extensive parametric study was undertaken to extend the available results over a wide range of crosssection slendernesses, inner tube strengths and concrete grades. The experimentally and numerically derived data were then employed to assess the applicability of the existing European, Australian and North American design provisions for composite carbon steel members to the design of the studied CFDST cross-sections. Overall, the existing design rules are shown to provide generally safe-sided (less so for the higher concrete grades) but rather scattered capacity predictions. Use of an effective concrete strength is recommended for the higher concrete grades and shown to improve the consistency of the design capacity predictions.
\end{abstract}

Keywords: Concrete-filled double skin tubular (CFDST) sections; High strength steel; Numerical analysis; Stainless steel; Structural design; Testing.

\section{Introduction}

Concrete-filled double skin tubular (CFDST) sections consist of two metal tubesan outer tube and an inner tube-with concrete sandwiched between the tubes. CFDST sections inherit the high strength, stiffness and ductility of other composite sections, and provide good fire resistance since the concrete infill provides thermal protection to the inner tube [1]. The metal tubes also act as permanent and integral formwork for placing the concrete, reducing labour costs, materials and construction time. CFDST sections will typically be lighter than traditional concrete-filled steel tubular (CFST) sections owing to the absence of the inner concrete core, which may also lead to savings in foundation costs [2]. Potential applications of CFDST sections in practice include offshore structures [3] and bridge piers [4], and an early example of the use of CFDST members in a transmission tower is described in [5].

Stainless steel is gaining traction in the construction industry owing to its high corrosion resistance, ease of maintenance and aesthetic appeal [6]; the use of high strength steel elements is also increasing because of their excellent load-bearing capacity and potential for weight and cost savings. An innovative type of composite cross-section, i.e. a concrete-filled double skin tubular (CFDST) section with a stainless steel outer tube and a high strength steel inner tube, is proposed in this study. This 
composite section is designed such that the most favourable properties of the constituent materials are exploited to the greatest possible extent. The interaction between the metal tubes and the concrete results in efficient utilisation of the different materials by confining the concrete and delaying local buckling in the metal tubes, while the presence of the high strength steel inner tube allows the thickness of the stainless steel outer tube to be reduced, thus improving the cost-effectiveness of the system.

The idea of using double skin tubular sections originated in Britain, where double cylindrical shells filled with resin were used in a deep-water vessel [7]. In the late 1990s, CFDST members were investigated for their potential applications in offshore structures [3] and bridge piers [4]. From 2000 onwards, CFDST members have generated substantial interest among researchers, and a number of experimental and numerical investigations have been carried out to examine their structural performance. The influence of cross-sectional slenderness and concrete grade on the ultimate capacity and ductility of CFDST stub columns with mild steel circular hollow section (CHS) inner and outer tubes has been examined in [8-11]. The compressive performance of partially loaded [12] and tapered [5] CFDST sections, as well as CFDST sections in a corrosive chloride environment [13] has also been investigated. From the results of these tests, it has been concluded that the cross-sectional slenderness and concrete strength have a significant influence on the structural behaviour of CFDST stub columns.

The structural behaviour of bare stainless steel tubular sections is known to be different from that of carbon steel sections [14-16]. Uy et al. [17] found that there is also a significant difference in structural performance between stainless steel CFST columns and carbon steel CFST columns. The behaviour and load-bearing capacity of concrete-filled stainless steel columns have also been studied [18-22]. Together, these studies have documented the rather more rounded and ductile load-deformation responses of stainless steel CFST stub columns compared to those of carbon steel CFST stub columns. This may be attributed to the rounded stress-strain behaviour and substantial strain hardening exhibited by stainless steel. With regard to CFDST stub columns with stainless steel outer tubes, existing studies are very limited. Han et al. [23] carried out a series of tests on straight, tapered and inclined stub columns, and concluded that the inclination and tapering both had a moderate negative influence on load-carrying capacity. Wang et al. [24] conducted a comprehensive experimental study of CFDST stub columns with stainless steel outer tubes; comparisons were also made between the test results and resistance predictions calculated using existing design rules. The resistance predictions were found to be rather scattered and it was shown that improved predictions could be achieved through the use of a modified local buckling coefficient to reflect the restraining effect of the concrete on the steel section and a concrete strength reduction factor for the higher concrete grades.

In addition to experimental studies, a series of numerical investigations into the structural behaviour of CFDST stub columns using CHS for both the inner and outer tubes has also been performed. In 2010, Huang et al. [25] proposed an adjustment to the confinement factor used in a previous confined concrete stress-strain model [26] for CFST to adapt the model for application to CFDST. This adjusted model was subsequently employed to simulate the structural performance of a range of CFDST members, including columns subjected to sustained loading [27], columns with preload [2], tapered columns under eccentric compression [28], CFDST members under local 
bearing forces [29] and CFDST sections with external stainless steel tubes under axial compression [30]. A further refined model proposed by Tao et al. [31], which adopts the concept of the confinement factor $(\xi)$ from [26], has been shown to be more versatile and provide accurate results in modelling CFST columns, especially with high-strength concrete or thin-walled tubes. This model was modified and employed herein to simulate the axial compressive behaviour of the studied CFDST sections. Previous numerical studies of the axial compressive behaviour of CHS-CHS CFDST stub columns have indicated the significant influence of the cross-sectional slendernesses of the outer and inner tubes on the confining stresses afforded to the concrete [25, 32, 33]. Although the structural behaviour of CFDST members has been explored in a number of previous experimental and numerical studies, to date, there have been no experimental or numerical investigations into CFDST stub columns with stainless steel outer tubes and high strength steel inner tubes, and this is therefore the focus of the present study.

In the current paper, a test programme on concrete-filled double skin tubular (CFDST) stub columns with stainless steel outer tubes and high strength steel inner tubes is first presented. A numerical modelling programme is then described, in which finite element (FE) models were initially developed to replicate the test results and then utilised to carry out an extensive parametric study to expand the available data pool to a wide range of cross-section slendernesses and material strengths. All the numerically derived data, together with the experimental results, are compared with the strength predictions from the European Code EN 1994-1-1 (EC4) [34], Australian Standard AS 5100 [35] and American Specifications AISC 360 [36] and ACI 318 [37], enabling the applicability of these existing design rules to the studied CFDST cross-sections to be assessed. Finally, modifications to the existing design rules are proposed and evaluated through reliability analysis.

\section{Experimental investigation}

\subsection{General}

A total of 23 CFDST stub column tests was conducted in this study. As shown in Fig. 1, the studied CFDST cross-sections featured stainless steel circular hollow sections (CHS) as the outer tubes and high strength steel CHS as the inner tubes. Two crosssection sizes - CHS 140×3 (Diameter $\times$ thickness) and CHS $165 \times 3$-were employed for the outer tubes in this study, which were cold-rolled from flat strips of Grade EN 1.4301 austenitic stainless steel, with measured $0.2 \%$ proof stresses of 300 and 276 $\mathrm{MPa}$, respectively. For the inner tubes, both hot-rolled seamless (CHS 22×4, 32×6, $38 \times 8,55 \times 11)$ and cold-formed (CHS $89 \times 4)$ high strength steel tubes were adopted, with measured $0.2 \%$ proof stresses ranging from 433 to $1029 \mathrm{MPa}$. The measured overall diameter-to-thickness ratios of the outer tubes ranged from 48.0-56.9, while those of the inner tubes ranged from 5.0-22.9. The nominal length $(L)$ of each stub column was designed to be 2.5 times the nominal diameter of the outer tube $\left(D_{o}\right)$, which was regarded as an appropriate length to include a representative pattern of residual stresses and geometric imperfections yet prohibit overall buckling.

In the preparation of the test specimens, the inner tubes were carefully positioned at the centroid of the outer tubes, and then steel strips of $10 \mathrm{~mm}$ depth and $2 \mathrm{~mm}$ thickness were welded near the ends of the specimens, as shown in Fig. 2. The specimens were 
then wire cut at both ends to ensure the ends of the outer and inner tubes lay in the same plane. The concrete was filled in the annulus between the outer and inner tubes and compacted using a poker vibrator to eliminate air bubbles in the freshly poured concrete. Three different concrete cylinder strengths of 40,80, $120 \mathrm{MPa}$ were used. Prior to casting, strain visualisation grids were marked onto the outer surfaces of the outer tubes. Geometric measurements were carefully taken, and their average values are presented in Table 1 using the nomenclature from Fig. 1, where $L$ is the member length, $D_{o}$ and $D_{i}$ are the outer cross-section diameters of the outer and inner tubes, $t_{o}$ and $t_{i}$ are the material thicknesses of the outer and inner tubes, and $A_{o}, A_{i}$ and $A_{c}$ are the calculated cross-sectional areas of the outer tubes, inner tubes and concrete, respectively.

The CFDST test specimens were labelled such that the material, shape of the crosssection and nominal dimensions of both the outer and inner tubes, as well as the grade of the concrete infill, can be easily identified. For example, the label AC165×3HC32×6-C40R defines the following specimen: the first letter "A" refers to austenitic stainless steel, the second letter "C" signifies a CHS and this is followed by the nominal dimensions $\left(D_{o} \times t_{o}\right)$ of the CHS outer tube of $165 \times 3 \mathrm{~mm}$. The hyphens in the label separate the information relating to the outer tube, the inner tube and the concrete grade, so the notation "HC $32 \times 6$ " after the first hyphen refers to the inner tube where the letter " $\mathrm{H}$ " represents high strength steel, the letter " $\mathrm{C}$ " indicates a CHS and the nominal dimensions $\left(D_{i} \times t_{i}\right)$ are $32 \times 6 \mathrm{~mm}$. The term after the second hyphen describes the sandwiched concrete, where the letter "C" followed by the value of the concrete strength in MPa (40 MPa) designates the nominal concrete grade. For repeated tests, the letter " $\mathrm{R}$ " is added as a suffix to the label.

\subsection{Material properties of tubes}

The material properties of the stainless steel outer tubes and high strength steel inner tubes were obtained from longitudinal tensile coupon tests. The tensile coupon specimens for the cold-formed outer and inner tubes were extracted from the quarter position around the cross-section relative to the weld, whereas those for the seamless inner tubes were extracted from a random location within the cross-section, as shown in Fig. 3. The gauge lengths of the coupons extracted from the outer and inner tubes were $25 \mathrm{~mm}$ and $50 \mathrm{~mm}$, respectively. Two holes of $10.5 \mathrm{~mm}$ diameter were drilled and reamed $17 \mathrm{~mm}$ from each end of the coupons. Strain gauges were affixed on the midline of each side of the coupons at the mid-length. A calibrated extensometer (with either a 25 or $50 \mathrm{~mm}$ gauge length) was mounted onto the specimens through threepoint contact knife edges. A pair of steel rods was inserted into the drilled holes of the coupon to apply tensile force in an MTS $50 \mathrm{kN}$ testing machine. The coupon tests were conducted in accordance with the testing procedures detailed in Huang and Young [38]. Static loads were obtained by pausing the tests for $100 \mathrm{~s}$ to allow stress relaxation to occur near the proportional limit, the $0.2 \%$ proof stress and ultimate tensile strength.

The material properties obtained from the coupon tests are summarised in Table 2, including the static $0.2 \%$ proof stress $\left(\sigma_{0.2}\right)$, static tensile strength $\left(\sigma_{u}\right)$, Young's modulus $(E)$, elongation at fracture $\left(\varepsilon_{f}\right)$ based on the respective gauge lengths and compound Ramberg-Osgood parameters $(n$ and $m$ ) which describe the shape of the stress-strain curve [39-42]. The full stress-strain curves obtained from the tensile coupon tests for the stainless steel outer tubes and the high strength steel inner tubes are compared in Fig. 4. The curves were drawn in such a way that the average strain gauge readings were used from the origin to $1 \%$ strain beyond which the strain 
calculated from the extensometer readings was used until fracture. The results highlight the different material properties of the outer and inner tubes. It may be seen that the stainless steel outer tubes have lower $0.2 \%$ proof stresses and ultimate strengths, but more pronounced strain hardening and much higher ductility than the high strength steel inner tubes.

\subsection{Material properties of concrete}

The material properties of the concrete were determined from concrete cylinder tests. Three grades of concrete with nominal compressive cylinder strengths of 40,80, and $120 \mathrm{MPa}$ were prepared with commercially available materials, the concrete mix proportions of which are shown in Table 3. Condensed silica fume was added to the mix for the very high strength concrete $(120 \mathrm{MPa})$. For each batch of concrete, at least nine cylinders, with the standard size of $150 \times 300 \mathrm{~mm}$ (diameter $\times$ length), were cast and cured under the same environmental conditions as the CFDST test specimens. Concrete cylinders were tested at 28 days after casting and also at the same time as the respective stub column tests. The cylinder tests were conducted in accordance with the procedures set out in the American Specification ACI 318 [37]. The average measured compressive concrete cylinder strengths and the number of cylinder tests conducted are summarised in Table 4.

\subsection{Test setup and procedure}

A total 23 of stub column tests on the CFDST specimens was carried out in this study, with one specimen repeated to assess the reliability of the tests. All the specimens were tested under uniform axial compression in an INSTRON $5000 \mathrm{kN}$ capacity servocontrolled hydraulic testing machine. A typical CFDST stub column test setup is illustrated in Fig. 5. Four $50 \mathrm{~mm}$ range transducers (LVDTs) were utilised to monitor the axial deformations of the test specimens, the layout of which is depicted in Fig. 6. The LVDTs were placed between the top and bottom plates of the testing machine at evenly located positions to obtain the average axial shortening of the specimens. Meanwhile, two pairs of longitudinal and transverse strain gauges were affixed at $1 / 3$ and $2 / 3$ points along the stub column lengths in order to monitor the strain development histories. These strain gauges were attached to the outer surface of the outer tube at the quarter position around the cross-section relative to the weld, as shown in Fig. 6. The strain gauge readings were also used to eliminate the elastic deformation of the end platens of the test machine from the end shortening measurements of the LVDTs and determine the true average axial strain values, following the procedures recommended in [43]. The modified true axial strain curves are employed for the validation of the FE models in Section 3.

A steel ring with a width of $25 \mathrm{~mm}$ was fixed near each end of the stub columns before testing to prevent "elephant foot" failure caused by end effects. Plaster material was used to fill any small gaps due to concrete shrinkage at the specimen ends. The plaster was left to harden under an initial load of approximately $2 \mathrm{kN}$. These procedures eliminated any possible gaps between the top and bottom surfaces of the specimens and the end plates of the testing machine. Thus, the load was applied uniformly across the whole cross-section. Displacement control was used to drive the load actuator, which allows the test to be continued beyond the ultimate load and the post-ultimate behaviour to be recorded. The stub column tests were performed at a constant rate of $0.4 \mathrm{~mm} / \mathrm{min}$. 
The applied load, LVDT readings and strain gauge readings were recorded by a data logger at $1 \mathrm{~s}$ intervals during the tests.

\subsection{Test results}

The compressive behaviour of the CFDST stub columns was observed during the tests. The load $(P)$ versus axial strain $(\varepsilon)$ relationships for each column specimen are presented in Fig. 7, where $P$ is the applied load recorded from the actuator and $\varepsilon$ is determined as the average axial shortening $(\Delta)$ divided by the stub column length $(L)$. The ultimate experimental loads $\left(P_{\text {exp }}\right)$ of the CFDST stub columns are presented in Table 1. It should be noted that the peak loads of four stocky specimens (as marked by a $*$ in Table 1) were not obtained since the load-average axial strain curves were still rising even at very high plastic strains. In these cases, the ultimate load for each of these four specimens was determined as the load where the slopes of the load-average axial strain curves reached $1 \%$ of their initial stiffness, as proposed in [44]. The ductility of the CFDST stub columns was assessed through the ductility index $(D I)[24,45]$, which is defined as the ratio of the axial displacement when the load drops to $85 \%$ of the ultimate load $\left(\Delta_{85 \%}\right)$ to the axial displacement at the ultimate load $\left(\Delta_{u}\right)$, as presented in Table 1. It may be observed that the tested specimens with $\mathrm{C} 40$ and $\mathrm{C} 80$ concrete infill generally possessed high ductility. The use of high strength concrete was shown to enhance the cross-section compressive resistance of the CFDST cross-sections but also to result in a reduction in ductility.

Two types of failure mode were observed for the tested stub columns, typical examples of which are presented in Fig. 8. Outward only local buckling of the outer tubes was detected for all the tested specimens (see Fig. 8(a) and (b)) due to the presence of the concrete, which inhibits inward deformations. Inward only local buckling of the high strength steel inner tube was detected in specimen AC140×3-HC89×4-C40, whereas no obvious local buckling of the inner tube was found in specimen AC140×3HC55×11-C40, as shown in Fig. 8(c) and (d). These different failure modes relate to both the different cross-sectional slendernesses of the inner tubes and the relative slendernesses of the inner and outer tubes. Concrete crushing was also observed in the regions where local buckling of the outer tubes occurred, and the concrete crushing may indeed have triggered the local buckling failures. The observed failure modes are similar to those described in Refs [8-11, 25, 32, 33] for CHS-CHS CFDST stub columns with carbon steel tubes.

\section{Numerical modelling}

\subsection{General}

Owing to the expense and impracticality of generating comprehensive data through experimentation, a numerical study was undertaken in parallel with the laboratory testing programme. The general purpose finite element (FE) analysis package ABAQUS [46] was employed throughout the study. The FE model was first validated against the experimental results by comparing ultimate loads, load-deformation histories and failure modes. Once satisfactory agreement between the experimental and numerical results was achieved, an extensive parametric study comprising 239 simulations was conducted to investigate the influence of the key variables on the structural response of the studied CFDST cross-sections in compression. 


\subsection{Basic modelling assumptions}

The geometry, loading and experimentally observed failure modes of the studied CFDST specimens were doubly symmetric; hence only one-eighth of the stub columns was modelled to enhance computational efficiency, with suitable boundary conditions applied to the planes of symmetry, as depicted in Fig. 9. In order to simulate the fixed ends employed in the tests, the top surface of the modelled stub columns was coupled to a reference point, where all degrees of freedom were restrained except for longitudinal translation. The compressive load was then applied using displacement control through the reference point at the end.

The finite element model was developed using four-noded doubly curved shell elements with reduced integration (S4R) for the metal tubes and eight-noded brick elements with three translational degrees of freedom at each node (C3D8R) for the concrete, in line with previous numerical investigations of concrete-steel composite columns [47-52]. Convergence studies [53] were conducted to decide upon an appropriate mesh density, with the aim of 3 . A uniform mesh size of $\pi D / 80$ and $D / 20$, where $D$ is the tube diameter, was assigned along the circumferential and longitudinal directions of the model, respectively.

For the validation of the model, the measured cross-section dimensions and material properties from the test specimens were incorporated into the respective FE simulations, while selected measured stress-strain curves were employed in the parametric studysee Section 3, 4 and Table 2. The engineering stress-strain curves obtained from the coupon tests, which comprised at least 100 intervals to accurately capture the full range stress-strain response, were converted into true stress-logarithmic plastic strain curves for input into ABAQUS. The relationships between true stress $\left(\sigma_{\text {true }}\right)$ and engineering stress $\left(\sigma_{\text {nom }}\right)$, and $\log$ plastic strain $\left(\varepsilon_{l n}{ }^{p l}\right)$ and engineering strain $\left(\varepsilon_{n o m}\right)$, are given by Eqs. (1) and (2), respectively. The classical metal plasticity model [46] using the von Mises yield criterion and isotropic hardening was adopted for both the outer and inner tubes.

$$
\begin{gathered}
\sigma_{\text {true }}=\sigma_{\text {nom }}\left(1+\varepsilon_{\text {nom }}\right) \\
\varepsilon_{\mathrm{ln}}^{p l}=\ln \left(1+\varepsilon_{\text {nom }}\right)-\frac{\sigma_{\text {nom }}}{E}
\end{gathered}
$$

The concrete damage plasticity (CDP) model defined in ABAQUS [46] was used for the sandwiched concrete. In order to account for the effect of confinement provided by the metal tubes, a confined concrete model based on that proposed by Tao et al. [31] was adopted in this study. The model in [31] was originally proposed and calibrated for CFST stub columns under axial compression. For CFDST stub columns, the inner tube restricts the inward deformation of the sandwiched concrete; thus, the concrete exhibits similar behaviour to that in CFST stub columns [25], and the model in [31] was therefore employed herein. For application to CFDST members, the confinement factor $\left(\xi_{\mathrm{c}}\right)$ for CFST was modified, as given by Eqs. (3) and (4),

$$
\xi_{c}=\frac{A_{o} \sigma_{0.2, o}}{A_{c e} f_{c}}
$$

$$
A_{c e}=\frac{\pi}{4}\left(D_{o}-2 t_{o}\right)^{2}
$$


where $A_{o}$ is the cross-sectional area of the outer tube, $A_{\mathrm{ce}}$ is an equivalent cross-sectional area of the concrete, $\sigma_{0.2, o}$ is the $0.2 \%$ proof stress of the stainless steel outer tube and $f_{c}$ is the compressive cylinder strength of the concrete. Values of the following parameters: the ratio of the second stress invariant on the tensile meridian to that on the compressive meridian $\left(K_{c}{ }^{*}\right)$, the dilation angle $(\psi)$, the flow potential eccentricity $(e)$, the ratio of the compressive strength under biaxial loading to uniaxial compressive strength $\left(f_{b o} / f_{c}{ }^{\prime}\right)$, and viscosity parameter $(\mu)$ were determined in accordance with the recommendations given in [31]. Following the guidance given in ACI 318 [37], the modulus of elasticity $E_{c}$ of the concrete was taken as $4733 \sqrt{f_{c}}$, and the Poisson's ratio of the concrete was set equal to 0.2. The uniaxial tensile response of the concrete was assumed to be linear until the tensile strength (taken as $0.1 f_{c}$ ) was reached, beyond which the inelastic portion of the tensile stress-strain curve was characterised by means of fracture energy $\left(G_{F}\right)$, determined from Eq. (5),

$$
G_{F}=\left(0.0469 d_{\max }^{2}-0.5 d_{\max }+26\right)\left(\frac{f_{c}}{10}\right)^{0.7}
$$

334

where $f_{c}$ is in $\mathrm{MPa}$ and $d_{\max }$ is the maximum coarse aggregate size in mm, taken as 10 $\mathrm{mm}$ in the validation study, and as $20 \mathrm{~mm}$ in the parametric study.

Surface-to-surface contact has been successfully used to simulate the interaction between metal tubes and concrete in previous studies [31, 48, 49 etc.] and was also employed herein. "Hard contact" was specified in the normal direction, while the Coulomb friction model was employed to simulate the behaviour at the interface in the tangential direction. For the studied CFDST stub columns, the slip at both interfaces was insignificant since the metal tubes and the concrete deformed together under axial compression. Friction coefficients of $0.25,0.3$ and 0.6 were adopted by $\mathrm{Hu}$ et al. [32], Lam et al. [52], and Han et al. [26], respectively. In this study, a friction coefficient of 0.6 was employed, though the results were found to be relatively insensitive to variation in this parameter. Initial imperfections and residual stresses are known to influence the compressive behaviour of tubular cross-sections [15,16]. However, for CFDST stub columns, the effects of local geometric imperfections and residual stresses are substantially reduced by the presence of the concrete infill. In particular, the lateral pressure applied by the concrete to the steel tubes obviates the need to assign any geometry perturbation to induce local buckling while, at the same time, the support provided by the concrete lessens the sensitivity of the tubes to local instabilities. Local geometric imperfections and residual stressses were therefore ignored in the current FE simulations, and the suitability of this assumption is confirmed in Section 3.3.

\subsection{Validation of numerical models}

The accuracy of the FE model was evaluated by comparing the test ultimate loads, full load-deformation histories and failure modes with those derived from the numerical simulations. Table 1 reports the ultimate loads predicted by FE analysis $\left(P_{F E}\right)$ and the ratios of the numerical to experimental ultimate loads $\left(P_{F E} / P_{\text {exp }}\right)$. As can be seen from Table 1, the model provides both accurate and consistent predictions of the ultimate loads, with the mean value of $P_{F E} / P_{\exp }$ equal to 0.97 and the coefficient of variation (COV) of 0.042. A typical series of the experimental load-deformation histories are compared with those from the numerical simulations in Fig. 10, where load is plotted 
against average axial strain. These comparisons reveal that the full experimental loading histories are accurately replicated by the FE simulations. Excellent agreement is also obtained between the test and numerical failure modes. The FE model was able to capture the failure modes of both the outer and inner tubes consistently, as depicted in Fig. 8(a), (b) and Fig. 8(c), (d), respectively. Overall, it maybe concluded that the FE model developed in this study is capable of accurately replicating the structural behaviour and ultimate response observed in the experiments, and is thus suitable for conducting parametric studies.

\subsection{Parametric studies}

Upon validation of the FE model, an extensive parametric study was conducted to generate further numerical data over a wider range of slendernesses of the outer and inner tubes, strengths of the inner tube and concrete grades. The measured stress-strain curve of the austenitic stainless steel AC140 $\times 3$ section was employed for all the modelled outer tubes, while three different grades of high strength steel inner tube with nominal $0.2 \%$ proof stresses $\left(\sigma_{0.2, i}\right)$ of 460,740 and $1100 \mathrm{MPa}$ were employed, adopting the respective measured stress-strain curves highlighted in Table 2. The outer diameter of the modelled outer tubes ranged from $200 \mathrm{~mm}$ to $600 \mathrm{~mm}$, with the thickness varying between $2 \mathrm{~mm}$ and $20 \mathrm{~mm}$, resulting in the ratios of $D_{\mathrm{o}} / t_{\mathrm{o}}$ ranging from 10 to 200 , covering compact, noncompact and slender cross-sections, according to the slenderness limits in AISC 360 [36]. The local slendernesses of the inner tubes were also varied from 8 to 150 . Three concrete strengths, 40, 80 and $120 \mathrm{MPa}$, were adopted for the sandwiched concrete. The ranges of the abovementioned parameters are summarised in Table 5. For all the modelled specimens, the stub column lengths were set equal to 2.5 times the outer diameters $\left(D_{o}\right)$, in accordance with the tested specimens. Overall, a total of 239 CFDST specimens was modelled in the parametric study.

\section{Discussion and assessment of current design methods}

\subsection{General}

Concrete-filled double skin sections with either carbon steel or stainless steel tubes are not explicitly covered by current design codes. Nonetheless, existing design rules for concrete-filled tubes in the European Code EN 1994-1-1 [34], Australian Standard AS 5100 [35] and two American Specifications AISC 360 [36] and ACI 318 [37] are described and assessed. The applicability of these design rules to CFDST sections is evaluated through comparisons of the experimental and numerical axial capacities with the predicted axial capacities $\left(P_{\mathrm{u}} / P_{\text {code }}\right)$, as reported in Table 6 . Note that all comparisons have been made based on the measured material and geometric properties and on the unfactored design strengths. Limitations specified in the codes on crosssectional slendernesses and material strengths are summarised in Table 7. The code limitations on concrete strength and steel strength are often exceeded, but comparisons are still presented in order that possible extension of the range of applicability of the codes can be assessed.

\subsection{European Code EN 1994-1-1 (EC4)}

The compressive design resistance of concrete-filled columns with circular carbon steel outer tubes given in EC4 [34] accounts for the beneficial confining effect of the 
steel tube on the concrete, but also the corresponding reduction to the strength of the steel tube caused by the circumferential stresses arising due to the restriction of the lateral expansion of the concrete. For the comparisons made herein, the EC4 resistance function is adopted, but with the following modifications: stainless steel is used in place of carbon steel for the outer tube, and hence the yield stress is replaced by the $0.2 \%$ proof stress, and the term in the EC4 [34] resistance function relating to the reinforcing bars is replaced by an equivalent term for the high strength steel inner tube. The crosssection capacity $\left(P_{\mathrm{EC} 4}\right)$ of the studied circular CFDST compression members is thus predicted using Eq. (6).

$$
P_{E C 4}=\eta_{o} A_{o} \sigma_{0.2, o}+A_{c} f_{c}\left(1+\eta_{c} \frac{t_{o}}{D_{o}} \frac{\sigma_{0.2, o}}{f_{c}}\right)+A_{i} \sigma_{0.2, i}
$$

where $\eta_{o}$ and $\eta_{c}$ are slenderness dependent, as given by Eqs. (7) and (8)

$$
\begin{gathered}
\eta_{o}=0.25(3+2 \bar{\lambda}) \leq 1.0 \\
\eta_{c}=4.9-18.5 \bar{\lambda}+17 \bar{\lambda}^{2} \geq 0
\end{gathered}
$$

where $\bar{\lambda}$ is the relative member slenderness, as defined in EC4 [34]. Note that the effective length factor was taken as 0.5 in the present study to reflect the fixed-ended boundary conditions employed in the tests and FE simulations.

A limit on the local slenderness of the outer tube of $D / t \leq 90\left(235 / f_{y}\right)$ is specified in EC4 [34], beyond which local buckling needs to be explicitly accounted for. In this study, the limit has been modified for stainless steel to consider the differences in material yield strength and Young's modulus; the modified limit is given by $D_{o} / t_{o} \leq$ $90\left(235 / \sigma_{0.2, o}\right)\left(E_{o} / 210000\right)$. It is worth noting that this limit for concrete-filled tubes is the same as the class 3 slenderness limit for unfilled tubes, i.e. the beneficial effect of the concrete infill in inhibiting inward local buckling of the outer tube is ignored. Further investigation is recommended to determine a more appropriate limit for concrete filled tubes. For unfilled CHS exceeding the above slenderness limit, an effective area formula $\left(A_{e}\right)$ has been developed by Chan and Gardner [54], based on an existing formulation in BS5950-1 [55]. This formula has been modified to reflect the material properties of stainless steel and is given by Eq. (9); this formula is applied herein when predicting the EC4 axial compressive resistance of slender CFDST crosssections.

$$
A_{e}=A\left(\frac{90}{D_{o} / t_{o}} \frac{235}{\sigma_{0.2}} \frac{E_{o}}{210000}\right)^{0.5}
$$

A comparison of the test and FE results with the strength predictions from EC4 [34] is shown in Fig. 11(a), where the ratio of test (or FE) strength-to-predicted strength $\left(P_{u} / P_{\mathrm{EC} 4}\right)$ has been plotted against the local slenderness of the outer tube $\lambda_{E C}=$ $\left(D_{o} / t_{o}\right)\left(\sigma_{0.2, o} / 235\right)\left(210000 / E_{o}\right)$. A limiting value of 90 is also plotted in Fig. 11(a). There is a trend that as slenderness increases, EC4 [34] yields less conservative but less scattered predictions. The conservatism at low slenderness values may be attributed to the lack of consideration of strain hardening in the stainless steel outer tube and the high strength steel inner tube. 
The mean ratio of the experimental and numerical results $\left(P_{u}\right)$ to the strength predictions from EC4 $\left(P_{\mathrm{EC} 4}\right)$ is equal to 1.01 and the corresponding $\mathrm{COV}$ is 0.091 , as reported in Table 6. It can be seen that the design provisions in EC4 [34] developed for concrete-filled carbon steel tubular sections offer generally good average strength predictions for CFDST stub columns with stainless steel outer tubes, though there are many cases where the strength predictions are on the unsafe side.

\subsection{Australian Standard AS 5100}

The Australian Standard AS 5100 [35] and the European Code EC4 [34] generally employ the same approach to the calculation of design strengths for concrete-filled CHS compressive members, with the nominal AS 5100 section capacity $\left(P_{\text {AS5100 }}\right)$ being equivalent to that given by Eq. (6). The class 3 (or yield) slenderness limit in the Australian Standard is however different from that in EC4 [34]. For a cross-section to be considered fully effective, the local slenderness $\left(\lambda_{A S}\right)$ should be less than the yield slenderness limit of 82 for cold-formed circular tubes, where $\lambda_{A S}$ is defined, replacing the yield stress with the $0.2 \%$ proof stress of the stainless steel outer tube, by Eq. (10).

$$
\lambda_{A S}=\frac{D_{o}}{t_{o}} \frac{\sigma_{0.2, o}}{250}
$$

For CHS beyond this limit, an effective cross-sectional area is implemented in the calculation of the design strengths of the specimens. The effective area of the stainless steel outer tube $\left(A_{e}\right)$ is obtained from Eqs. (11)-(13), which are taken from AS/NZS 4673 [56],

$$
A_{e}=\left\{1-\left[1-\left(\frac{E_{t}}{E_{o}}\right)^{2}\right]\left[1-\left(\frac{A_{r}}{A_{o}}\right)\right]\right\} A_{o}
$$

$$
A_{r}=K_{c} A=\min \left\{1, \frac{(1-C)\left(E_{o} / \sigma_{0.2, o}\right)}{\left(3.226-\lambda_{c}\right)\left(D_{o} / t\right)}-\frac{0.178 C}{3.226-\lambda_{c}}\right\} A_{o}
$$

$$
E_{t}=\frac{E_{o} \sigma_{0.2, o}}{\sigma_{0.2, o}+0.002 n E_{o}\left(F_{n} / \sigma_{0.2, o}\right)^{n-1}}
$$

where $E_{t}$ is the tangent modulus in compression corresponding to the buckling stress, $A_{r}$ is the reduced area of the cross-section, $C$ is the ratio of the proportionality stress to the yield stress, $\lambda_{c}$ is equal to $3.084 \mathrm{C}, K_{c}$ is the strength reduction factor for slender cross-sections, and $F_{n}$ is the flexural buckling stress of the column, which was taken equal to $\sigma_{0.2, o}$ for all the studied specimens due to the short column lengths.

The experimental and numerical results are compared with the AS 5100 [35] capacity predictions in Fig. 11 (b), where the ratio of test (or FE) strength-to-AS 5100 predicted strength $\left(P_{u} / P_{\mathrm{AS} 5100}\right)$ is plotted against the cross-sectional slenderness $\left(\lambda_{A S}\right)$. Similar observations emerge from Fig. 11(b) that AS 5100 [35] provides less conservative but less scattered strength predictions with increasing slenderness. The conservatism in the compact region is again attributed to the lack of account taken of strain hardening of the metal tubes. A numerical evaluation of the AS 5100 strength predictions is reported in Table 6 , showing a high level of accuracy with the mean ratio 
of $P_{u} / P_{\mathrm{AS} 5100}$ equal to 1.00 and the corresponding COV equal to 0.097. Similar to the conclusions reached for EC4, the application of the AS 5100 design rules to the studied CFDST sections generally yields relatively good average capacity predictions but with a substantial number on the unsafe side.

\subsection{American specifications AISC 360 and ACI 318}

The AISC 360 [36] rules for the design of filled composite members with carbon steel outer tubes are also adopted herein to predict the axial capacity of the studied CFDST stub columns. The AISC 360 compressive cross-section strengths $\left(P_{\text {AISC }}\right)$ of the columns are calculated according to the compactness of the composite section. Filled composite sections are categorised as compact, noncompact or slender according to the diameter-to-thickness ratios of their outer tubes. A compact section can reach the yield strength of the metal tube and develop a concrete compressive strength of $0.95 f_{c}$ due to the high level of confinement provided by the metal tube. A noncompact section can also reach the yield strength of the metal tube, but is deemed to confine the concrete to a lesser extent than a compact section due to local buckling [57]; hence $0.70 f_{c}$ is used in the design calculation. A slender section can neither develop the yield strength of the metal tube nor confine the concrete beyond $0.70 f_{c}$ [58]. The limiting $D_{o} / t_{o}$ values, i.e. $\lambda_{p}$ for compact/noncompact and $\lambda_{r}$ for noncompact/slender, are detailed in Table 8 and plotted in the Fig. 11(b).

In this study, the yield stress was again taken as the $0.2 \%$ proof stress in calculating the column strengths, and the term relating to the reinforcing bars is also again replaced by the cold-formed high strength steel inner tube. However, the structural behaviour of the inner tube is different from that of reinforcing bars. Reinforcing bars have little or no axial resistance upon crushing of the concrete, whereas the inner tube still continues to sustain load and thus, departing from the treatment for reinforcing bars in AISC 360, is considered herein as an independent term in the resistance function. Hence, the AISC 360 compressive cross-section strengths $\left(P_{\text {AISC }}\right)$ of the studied columns with compact, noncompact and slender sections are determined from Eq. (14).

$$
P_{\mathrm{AISC}}= \begin{cases}A_{o} \sigma_{0.2, o}+0.95 f_{c} A_{c}+A_{i} \sigma_{0.2, i} & (\text { Compact }) \\ P_{y}+\frac{P_{p}-P_{y}}{\left(\lambda_{r}-\lambda_{p}\right)^{2}}\left(\lambda_{r}-\lambda\right)^{2}+A_{i} \sigma_{0.2, i} & \text { (Noncompact) } \\ A_{o} f_{c r}+0.7 f_{c} A_{c}+A_{i} \sigma_{0.2, i} & \text { (Slender) }\end{cases}
$$

where $P_{p}$ and $P_{y}$ is determined from Eqs. (15) and (16) respectively, $\lambda=D_{o} / t_{\mathrm{o}}$ is the slenderness of the outer tube and $f_{c r}$ is the elastic critical buckling stress of the outer tube, given by Eq. (17).

$$
P_{p}=A_{o} \sigma_{0.2, o}+0.95 f_{c} A_{c}+A_{i} \sigma_{0.2, i}
$$

$$
P_{y}=A_{o} \sigma_{0.2, o}+0.7 f_{c} A_{c}+A_{i} \sigma_{0.2, i}
$$

$$
f_{c r}=\frac{0.72 \sigma_{0.2, o}}{\left[\left(\frac{D_{o}}{t_{o}}\right) \frac{\sigma_{0.2, o}}{E_{o}}\right]^{0.2}}
$$


The accuracy of the AISC 360 [36] design provisions is assessed by comparing the test (or FE) results with the described strength predictions, as shown in Fig. 11(c), where the ratios of test (or FE) strength-to-predicted strength have been plotted against the normalised cross-section slenderness $\lambda_{\text {AISC }}=\left(D_{o} / t_{0}\right)\left(\sigma_{0.2, o} / E_{o}\right)$. The comparisons show that AISC 360 generally results in rather conservative predictions across the range of compact, noncompact and slender sections. For compact sections, as the slenderness increases, the design method becomes less conservative, though generally remains on the safe side. For noncompact and slender sections, the capacity predictions tend to become generally more conservative and more scattered with increasing slenderness. This may indicate that AISC 360 [36] underestimates the level of confinement afforded to the concrete and the strength of the metal tubes in this slenderness range. The mean ratio of the experimental and numerical results $\left(P_{u}\right)$ to the strength predictions from AISC $360\left(P_{A I S C}\right)$ is equal to 1.20 with a COV of 0.119 , as reported in Table 6. This confirms that AISC 360 yields generally conservative and scattered strength predictions when applied to CFDST stub columns with stainless steel outer tubes.

The American Concrete Institute design guidelines ACI 318 [37] for concrete-filled tubular sections are also assessed herein. The compressive design resistance $\left(P_{\mathrm{ACI}}\right)$ for concrete-filled tubular sections, modified as above for application to CFDST sections with outer stainless steel tubes, is given by Eq. (18).

$$
P_{\mathrm{ACI}}=A_{o} \sigma_{0.2, o}+0.85 A_{c} f_{c}+A_{i} \sigma_{0.2, i}
$$

It should be noted that the use of the gross area of the outer tube requires its thickness to satisfy $t_{o} \geq D_{o}\left(\sigma_{0.2, o} / 8 E_{o}\right)^{0.5}[37]$. The compressive design resistance of sections beyond this limit is not explicitly covered by ACI 318. To allow comparisons to be made herein, the effective area $\left(A_{e}\right)$ expression from the American Specification SEI/ASCE-8-02 was adopted to account for local buckling. The American Specification SEI/ASCE-8-02 [59] and Australian/New Zealand Specification AS/NZS 4673 [56] employ the same approach in determining the effective area $\left(A_{e}\right)$ of stainless steel crosssections, but with different coefficients used in calculating $K_{c}$, as given in Eq. (19).

$$
A_{o}=K_{c} A=\min \left\{1, \frac{(1-C)\left(E_{o} / \sigma_{0.2, o}\right)}{\left(8.93-\lambda_{c}\right)\left(D_{o} / t_{o}\right)}-\frac{5.882 C}{8.93-\lambda_{c}}\right\} A
$$

The accuracy of the ACI 318 [37] provisions is evaluated by comparing the test and FE results with the ACI 318 strength predictions, as shown in Fig. 11(d), where the ratios of test (or FE) strength-to-predicted strength $\left(P_{u} / P_{\mathrm{ACI}}\right)$ have been plotted against the normalised cross-section slenderness $\left(\lambda_{A C I}=\left(D_{o} / t_{\mathrm{o}}\right)\left(\sigma_{0.2, \mathrm{o}} / E_{\mathrm{o}}\right)^{0.5}\right)$. The comparisons show that ACI 318 [37] significantly underestimates the capacity of the studied crosssections with a high level of scatter across the full slenderness range. This may be attributed primarily to the fact that ACI 318 [37] does not differentiate between crosssections of different compactness, other than slender, nor does it consider concrete confinement effects. The mean ratio of $P_{u} / P_{\mathrm{ACI}}$ is equal to 1.24 with a COV of 0.106 , as reported in Table 6. This illustrates that ACI 318 [37] generally provides safe-sided, but rather conservative and scattered strength predictions for CFDST stub columns with stainless steel outer tubes. 


\subsection{Modification to design rules}

The ratios of $P_{u} / P_{\text {code }}$ are plotted against slenderness for each of the four considered design codes in Fig. 11(a)-(d); the data are categorised by concrete strength. The comparisons reveal that all the codes provide less conservative predictions for the specimens with high strength concrete (C80 and C120) than their counterparts with normal strength concrete (C40), particularly for sections within the specified code slenderness limits. This observation has previously been made for concrete-filled tubes [24]; to remedy this, the effective compressive strength in EN 1992-1-1 [60] is applied herein in the case of concrete strengths greater than $50 \mathrm{MPa}$ and below $90 \mathrm{MPa}$ for sections within the corresponding slenderness limit of each design code considered. The effective strength is determined by multiplying the concrete strength by a reduction factor $\eta$, as given by Eq. (20). For concrete strengths beyond $90 \mathrm{MPa}$, a constant reduction factor $\eta$ of 0.8 , as proposed by Liew et al. [61], is employed herein to determine the effective compressive strength. The values of $\eta$, as calculated from Eq. (20), are shown in Table 5 for the specimens tested in the present study.

$$
\eta=\left\{\begin{array}{lc}
1.0-\frac{f_{c}-50}{200} & 50 \mathrm{MPa}<f_{c} \leq 90 \mathrm{MPa} \\
0.8 & f_{c}>90 \mathrm{MPa}
\end{array}\right.
$$

The experimental and numerical results are compared with the modified capacity predictions in Fig. 12, where the ratios of test (or FE) strength-to-modified predicted strength $\left(P_{u} / P_{\mathrm{EC} 4 *}, P_{u} / P_{\mathrm{AS} 5100 *} P_{u} / P_{\mathrm{AISC}} *\right.$ and $\left.P_{u} / P_{\mathrm{ACI}} *\right)$ have been plotted against the normalised cross-section slenderness. The average ratios and the corresponding COVs of test (or FE)-to-modified predicted strengths for each concrete grade are also summarised in Table 9. The comparisons reveal that the inclusion of $\eta$ in the design rules leads to more consistent and less scattered resistance predictions across the different concrete strengths.

\subsection{Reliability analysis}

The reliability associated with the application of the current and modified EN 19941-1 design rules to the studied CFDST cross-sections is assessed through statistical analyses, in accordance with EN 1990 [62]. In the analyses, the mean to nominal yield strength ratios $f_{y, \text { mean }} / f_{y \text {,nom }}$ (i.e. the material over-strength) were taken as 1.30 [63] for the stainless steel and 1.135 [64] for the high strength steel, while the concrete overstrength ratio was determined from Eq. (21) [65],

$$
f_{c}=f_{m}-1.64 \delta
$$

where $f_{c}$ and $f_{m}$ are the characteristic and mean values of compressive concrete strength and $\delta$ is the standard deviation, taken as $0.026,0.040$ and 0.025 for C40, C80 and C120 concrete respectively, in accordance with the test results, as shown in Table 4. The COVs of the strength of stainless steel, concrete and high strength steel were taken as 0.06 [63], 0.18 [66] and 0.055 [67] respectively, while the corresponding COVs of the geometric properties was taken as 0.05 [63], 0.01 [66] and 0.02 [67]. The partial factors for the stainless steel, concrete and high strength steel were taken as 1.1 [68], 1.5 [62] and 1.0 [69]. 
The key parameters and results from the Eurocode reliability analysis are summarised in Table 10, where $k_{\mathrm{d}, \mathrm{n}}$ is the design (ultimate limit state) fractile factor, $b$ is the average ratio of test and FE resistances to design model resistance defined in [70], $V_{\delta}$ is the COV of the tests or FE simulations relative to the resistance model, $V_{\mathrm{r}}$ is the combined COV incorporating both model and basic variable uncertainties, and $\gamma_{\mathrm{M} 0}$ is the partial safety factor. As can be seen from Table 10, the required partial factors for the original and modified design rules are 0.99 and 0.97 , which are close to the currently adopted value of 1.0 in EN 1994-1-1 [34], and thus both the current and modified design rules are considered to satisfy the reliability requirements of EN 1990 [62]. A more consistent level of reliability across the range of concrete strengths is achieved using the modified design rules.

\section{Conclusions}

A comprehensive experimental and numerical investigation of CFDST stub columns with stainless steel outer tubes and high strength steel inner tubes has been conducted. The experimental programme comprised 23 stub columns tests, of which the ultimate load, load-deformation histories and failure modes were reported. The obtained test results were employed in a parallel numerical simulation programme for the validation of a finite element (FE) model. An extensive parametric study was then undertaken to extend the available results over a wide range of cross-section slendernesses, inner tube strengths and concrete grades. The derived test and FE data were used to assess the suitability of the existing design provisions of EC4, AS 5100, AISC 360 and ACI 318 for application to the studied CFDST cross-sections. Overall, the current design rules in EC4 [34] and AS 5100 [35] provide good average axial capacity predictions but result in a high number of strength predictions on the unsafe side, while AISC 360 [36] and ACI 318 [37] provide conservative but rather scattered predictions. Inaccuracies in the resistance models stemmed principally from the lack of consideration of strain hardening in the metal tubes and insufficient allowance for the strength benefits of concrete confinement applied to the concrete infill. Modifications incorporating the effective compressive strength of concrete were considered and shown to improve the consistency of the design predictions. The reliability of both the current and modified EC4 design rules was demonstrated by means of statistical analyses in accordance with EN 1990 [62]. Overall, it is concluded that while existing provisions are satisfactory, further improvements to the design rules for concrete-filled double skin tubular stub columns are required, and hence further research is underway in this area.

\section{Acknowledgements}

The authors are grateful to Mr. Cheuk Him Wong for his assistance in the experimental program as part of his final year undergraduate research project at the University of Hong Kong. The research work described in this paper was supported by a grant from the University of Hong Kong under the seed funding program for basic research. 


\section{References}

[1] H. Lu, L.H. Han, X.L. Zhao, Fire performance of self-consolidating concrete filled double skin steel tubular columns: Experiments. Fire Saf. J. 45(2) (2000) 106-115.

[2] W. Li, Q.X. Ren, L.H. Han, X.L. Zhao, Behaviour of tapered concrete-filled double skin steel tubular (CFDST) stub columns. Thin-Walled Struct. 57 (2012) 37-48.

[3] S. Wei, S.T. Mau, C. Vipulanandan, S.K. Mantrala, Performance of new sandwich tube under axial loading: experiment. J. Struct. Eng. 121(12) (1995) 1806-1814.

[4] K. Nakanishi, T. Kitada, H. Nakai, Experimental study on ultimate strength and ductility of concrete filled steel columns under strong earthquake. J. Constr. Steel Res. 51(3) (1999) 297-319.

[5] W. Li, L.H. Han, X.L. Zhao, Axial strength of concrete-filled double skin steel tubular (CFDST) columns with preload on steel tubes. Thin-Walled Struct. 56 (2012) 9-20.

[6] L. Gardner, Aesthetics, economics and design of stainless steel structures. Adv. Steel Constr. 4(2) (2008) 113-122.

[7] P. Montague, A simple composite construction for cylindrical shells subjected to external pressure. J. Mech. Eng. Sci. 17(2) (1975) 105-113.

[8] X.L. Zhao, R. Grzebieta, M. Elchalakani, Tests of concrete-filled double skin CHS composite stub columns. Steel and Compos. Struct. 2(2) (2002) 129-146.

[9] Z. Tao, L.H. Han and X.L. Zhao, Behaviour of concrete-filled double skin (CHS inner and CHS outer) steel tubular stub columns and beam-columns. J. Constr. Steel Res. 60(8) (2003) 1129-1158.

[10] K. Uenaka, H. Kitoh, K. Sonoda, Concrete filled double skin circular stub columns under compression. Thin-Walled Struct. 48(1) (2010) 19-24.

[11] X.L. Zhao, L.W. Tong, X.Y. Wang, CFDST stub columns subjected to large deformation axial loading. Eng. Struct. 32(3) (2010) 692-703.

[12] Y.F. Yang, L.H. Han, B.H. Sun, Experimental behaviour of partially loaded concrete filled double-skin steel tube (CFDST) sections. J. Constr. Steel Res. 71 (2012)71 63-73.

[13] W. Li, L.H. Han, X.L. Zhao. Behavior of CFDST stub columns under preload, sustained load and chloride corrosion. J. Constr. Steel Res. 107 (2015) 12-23.

[14] O. Zhao, L. Gardner, B. Young, Structural performance of stainless steel circular hollow sections under combined axial load and bending-Part 1: Experiments and numerical modelling. Thin-Walled Struct.101 (2016) 231-239.

[15] O. Zhao, L. Gardner, B. Young, Testing and numerical modelling of austenitic stainless steel CHS beam-columns. Eng. Struct. 111 (2016) 263-274.

[16] L. Gardner, A. Talja, N.R. Baddoo, Structural design of high-strength austenitic stainless steel. Thin-Walled Struct. 44(5) (2006) 517-28.

[17] B. Uy, Z. Tao, L.H. Han, Behavior of short and slender concrete-filled stainless steel tubular columns. J. Constr. Steel Res. 67(3) (2011) 360-378.

[18] D. Lam, L. Gardner, Structural design of stainless steel concrete filled columns. J. Constr. Steel Res. 64(11) (2008) 1275-1282.

[19] E. Ellobody, B. Young, Design and behaviour of concrete-filled cold-formed stainless steel tube columns. Eng. Struct. 28(5) (2006) 716-728.

[20] B. Young, E. Ellobody, Experimental investigation of concrete-filled cold-formed high strength stainless steel tube columns. J. Constr. Steel Res. 62(5) (2006) 484-492.

[21] D. Lam, J. Yang, A. Mohammed, Axial behavior of concrete filled lean duplex stainless steel square hollow sections. In Proceedings of 8th European Conference on Steel and Composite Struct, Copenhagen, Denmark, 2017, pp. 1956-1965.

[22] L. Li, Structural performance of concrete-filled cold-formed stainless steel members. PhD thesis, Department of Civil Engineering, Univ. Hong Kong, Hong Kong, China, 2017.

[23] L.H. Han, Q.X. Ren, W. Li, Tests on stub stainless steel-concrete-carbon steel doubleskin tubular (DST) columns. J. Constr. Steel Res. 67(3) (2011) 437-452. 
[24] F. Wang, B. Young, L. Gardner, Experimental study of CFDST sections with stainless steel SHS and RHS outer tubes under axial compression. J. Struct. Eng. (Under review).

[25] H. Huang, L.H. Han, Z. Tao, X.L. Zhao, Analytical behaviour of concrete-filled double skin steel tubular (CFDST) stub columns. J. Constr. Steel Res. 66(4) (2010) 542-555.

[26] L.H. Han, G.H. Yao, Z. Tao, Performance of concrete-filled thin-walled steel tubes under pure torsion. Thin-Walled Struct. 45(1) (2007) 24-36.

[27] L.H. Han, Y.J. Li, F.Y. Liao, Concrete-filled double skin steel tubular (CFDST) columns subjected to long-term sustained loading. Thin-Walled Struct. 49(12) (2011) 1534-1543.

[28] W. Li, Q.X. Ren, L.H. Han, X.L. Zhao, Behaviour of tapered concrete-filled double skin steel tubular (CFDST) stub columns. Thin-Walled Struct. 57 (2012) 37-48.

[29] C. Hou, L.H. Han, X.L. Zhao, Behaviour of circular concrete filled double skin tubes subjected to local bearing force. Thin-Walled Struct. 93 (2015) 36-53.

[30] F.C. Wang, L.H. Han, W. Li, Analytical behavior of CFDST stub columns with external stainless steel tubes under axial compression, Thin-Walled Struct. 127 (2018) 756-768.

[31] Z. Tao, Z.B. Wang, Q. Yu, Finite element modelling of concrete-filled steel stub columns under axial compression. J. Constr. Steel Res. 89 (2013) 121-131.

[32] H.T. Hu, F.C. Su, Nonlinear analysis of short concrete-filled double skin tube columns subjected to axial compressive forces. Mar. Struct. 24(4) (2011) 319-337.

[33] M. Pagoulatou, T. Sheehan, X.H. Dai, D. Lam, Finite element analysis on the capacity of circular concrete-filled double-skin steel tubular (CFDST) stub columns. Eng. Struct. 72 (2014) 102-112.

[34] EN 1994-1-1, Eurocode 4: Design of composite steel and concrete structures, Part 1.1: general rules and rules for buildings, Brussels: European Committee for Standardization (CEN), 2004.

[35] AS 5100.6-2004, Bridge design part 6: steel and composite construction, Sydney, Australia: Standards Australia, 2004.

[36] ANSI/AISC 360-16, Specification for structural steel buildings, American Institute of Steel Construction, Chicago, USA, 2016.

[37] ACI 318-14, Building code requirements for structural concrete and commentary, Michigan, USA, Farmington Hills, 2014.

[38] Y. Huang, B. Young,The art of coupon tests. J. Constr. Steel Res. 96 (2014) 159-175.

[39] E. Mirambell, E. Real, On the calculation of deflections in structural stainless steel beams: an experimental and numerical investigation. J. Constr. Steel Res. 54(1) (2000) 109-133.

[40] K.J. Rasmussen, Full-range stress-strain curves for stainless steel alloys. J. Constr. Steel Res. 59(1) (2003) 47-61.

[41] I. Arrayago, E. Real, L. Gardner, Description of stress-strain curves for stainless steel alloys. Mater. Des. 87 (2015) 540-552.

[42] L. Gardner, X. Yun, Description of stress-strain curves for cold-formed steels. Constr. Build. Mater. 189 (2018) 527-538.

[43] Centre for Advanced Structural Engineering, Compression Tests of Stainless Steel Tubular Columns, University of Sydney, Australia, 1990, Investigation report S770.

[44] G.B. dos Santos, L. Gardner, M. Kucukler, A method for the numerical derivation of plastic collapse loads. Thin-Walled Struct. 124 (2018) 258-277.

[45] Z. Tao, L.H. Han, X.L. Zhao. Tests on stub columns of concrete filled double skin rectangular hollow sections. In: Proceedings of the 4th international conference on thinwalled Structures. (2004). p. 885-892.

[46] ABAQUS. ABAQUS/standard user's manual. Version 6.17. Dassault Systemes Simulia Corp. USA, 2017.

[47] Y.D. Jiang, A. Silva, J.M. Castro, T.M. Chan, R. Monteiro, Experimental Study and Numerical Assessment of the Flexural Behaviour of Square and Rectangular CFST Members under Monotonic and Cyclic Loading. Key Eng. Mater. 763 (2018) 804-811. 
[48] A. Espinos, L. Gardner, M.L. Romero, A. Hospitaler, Fire behaviour of concrete filled elliptical steel columns. Thin-Walled Struct. 49(2) (2011) 239-255.

[49] W. Qiu, F. McCann, A. Espinos, M.L. Romero, L. Gardner, Numerical analysis and design of slender concrete-filled elliptical hollow section columns and beam-columns. Eng. Struct. 131 (2017) 90-100.

[50] M.F. Hassanein, Numerical modelling of concrete-filled lean duplex slender stainless steel tubular stub columns. J. Constr. Steel Res. 66(8-9) (2010) 1057-1068.

[51] J. Chen, J. Wang, F. Xie, W.L. Jin, Behavior of thin-walled dodecagonal section double skin concrete-filled steel tubes under bending. Thin-Walled Struct. 98 (2016) 293-300.

[52] D. Lam, X.H. Dai, L.H. Han, Q.X. Ren, W. Li. Behaviour of inclined, tapered and STS square CFST stub columns subjected to axial load. Thin-Walled Struct.54 (2012) 94-105.

[53] F. Wang, Behaviour and Design of Concrete-Filled Double Skin Stainless Steel Members. PhD thesis, Department of Civil Engineering, Univ. Hong Kong, Hong Kong, China, 2018.

[54] T.M. Chan, L. Gardner, Compressive resistance of hot-rolled elliptical hollow sections. Eng. Struct. 30(2) (2008) 522-532.

[55] BS 5950-1, Structural Use of Steelwork in Building- Part 1: Code of Practice for DesignRolled and Welded Sections, The Standards Policy and Strategy Committee, 2000.

[56] AS/NZS 4673 2001, Cold-formed stainless steel structures, Australian/New Zealand Standard, AS/NZS 4673:2001, Sydney, Australia: Standards Australia, 2001.

[57] W.F. Chen, D.J. Han, Plasticity for structural engineers. New York, USA: J. Ross Publishing; 2007.

[58] Z. Lai, A.H. Varma, K. Zhang, Noncompact and slender rectangular CFT members: Experimental database, analysis, design. J. Constr. Steel Res. 101 (2014) 455-468.

[59] SEI/ASCE 8-02, Specification for the design of cold-formed stainless steel structural members, Reston: American Society of Civil Engineers (ASCE), 2002.

[60] EN 1992-1-1, Eurocode 2: Design of concrete structures-Part 1-1: General rules and rules for buildings, Brussels: European Committee for Standardization (CEN), 2004.

[61] J.R. Liew, M. Xiong, D. Xiong, Design of concrete filled tubular beam-columns with high strength steel and concrete. Struct. 8 (2016) 213-226.

[62] EN 1990, Eurocode 0: basis ofstructural design. Brussels: European Committee for Standardization (CEN), 2008.

[63] S. Afshan, P. Francis, N.R. Baddoo, L. Gardner, Reliability analysis of structural stainless steel design provisions. J. Constr. Steel Res. 114 (2015) 293-304.

[64] J. Wang, S. Afshan, M. Gkantou, M. Theofanous, C. Baniotopoulos, L. Gardner, Flexural behaviour of hot-finished high strength steel square and rectangular hollow sections. J. Constr. Steel Res. 121 (2016) 97-109.

[65] Arya C. Design of structural elements. London: Spon Press; 2009.

[66] R. Lu, Y. Luo, J.P. Conte, Reliability evaluation of reinforced concrete beams. Struct. Saf. 14 (1994) 277-298.

[67] M. Byfield, D. Nethercot, Material and geometric properties of structural steel for use in design. Struct. Eng. 75 (1997) 363-367.

[68] EN 1993-1-4, Eurocode 3: design of steel structures - Part 1.4: general rules supplementary rules for stainless steels, Brussels: European Committee for Standardization (CEN), 2006.

[69] EN 1993-1-1, Eurocode 3: design of steel structures - Part 1. 1: general rules and rules for buildings, Brussels: European Committee for Standardization (CEN), 2005.

[70] X. Yun, L. Gardner, N. Boissonnade, The continuous strength method for the design of hot-rolled steel cross-sections. Eng. Struct. 157 (2018) 179-191. 


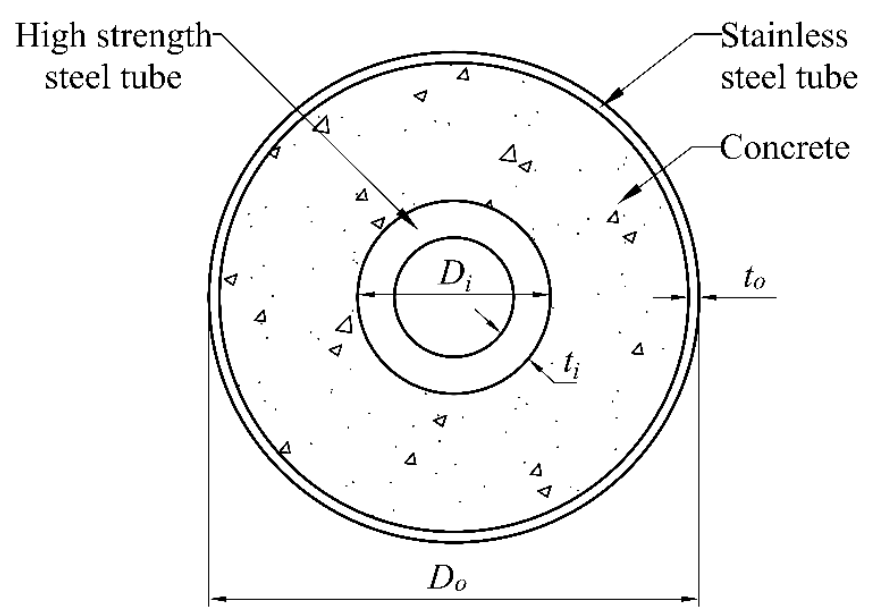

818 Fig. 1. Definition of symbols for concrete-filled double skin tubular stub column specimens.

819

820

821

822

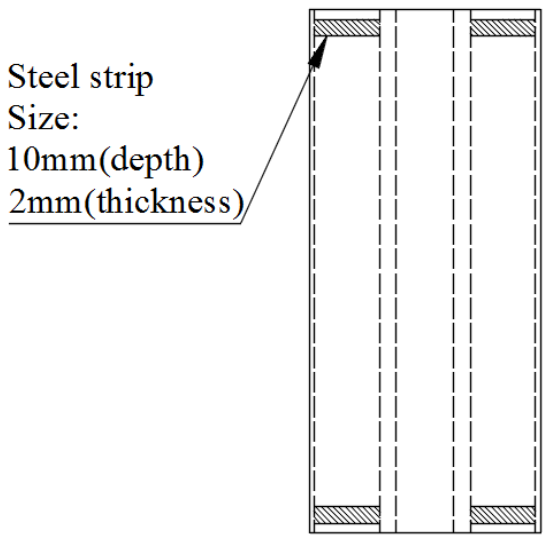

Fig. 2. Fabrication of the tubes prior to casting.

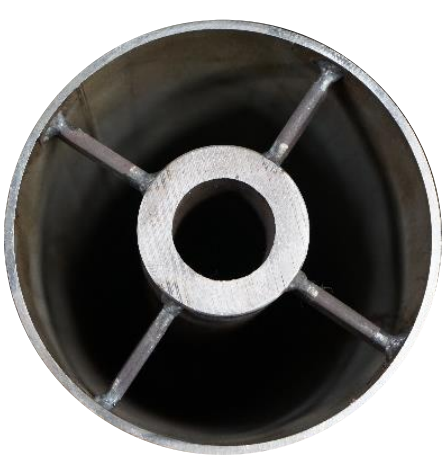

Size:

$10 \mathrm{~mm}($ depth$)$

2mm(thickness)
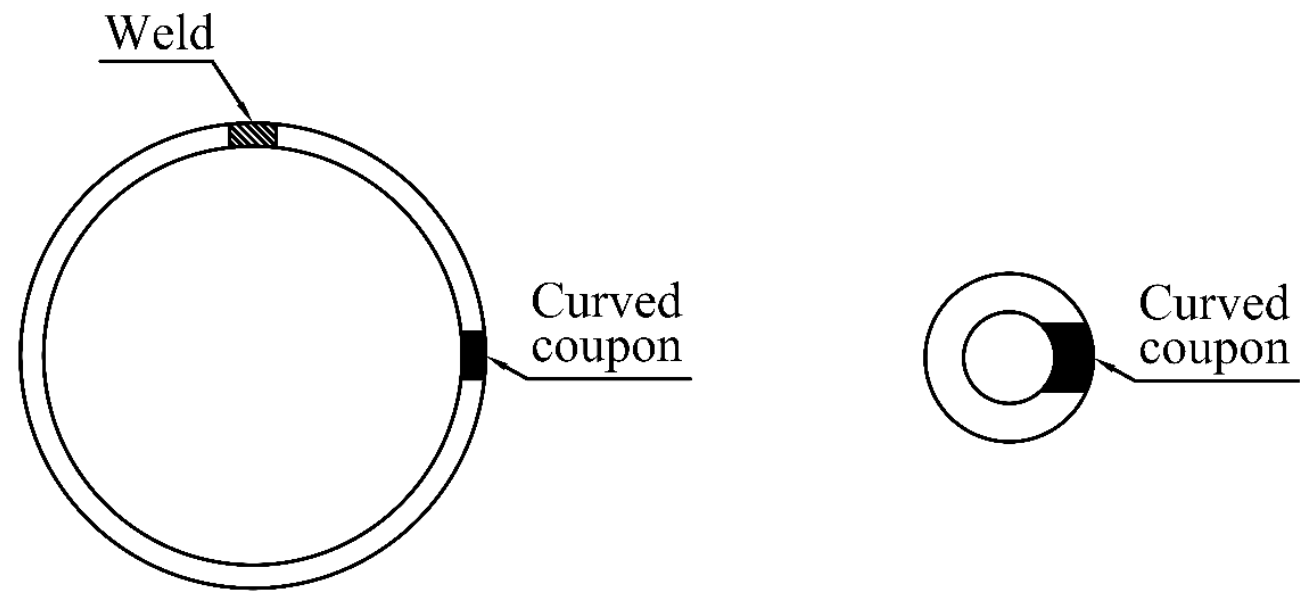

824

(a) Cold-formed tube

(b) Hot-rolled seamless tube

Fig. 3. Locations of tensile coupons within the cross-sections. 


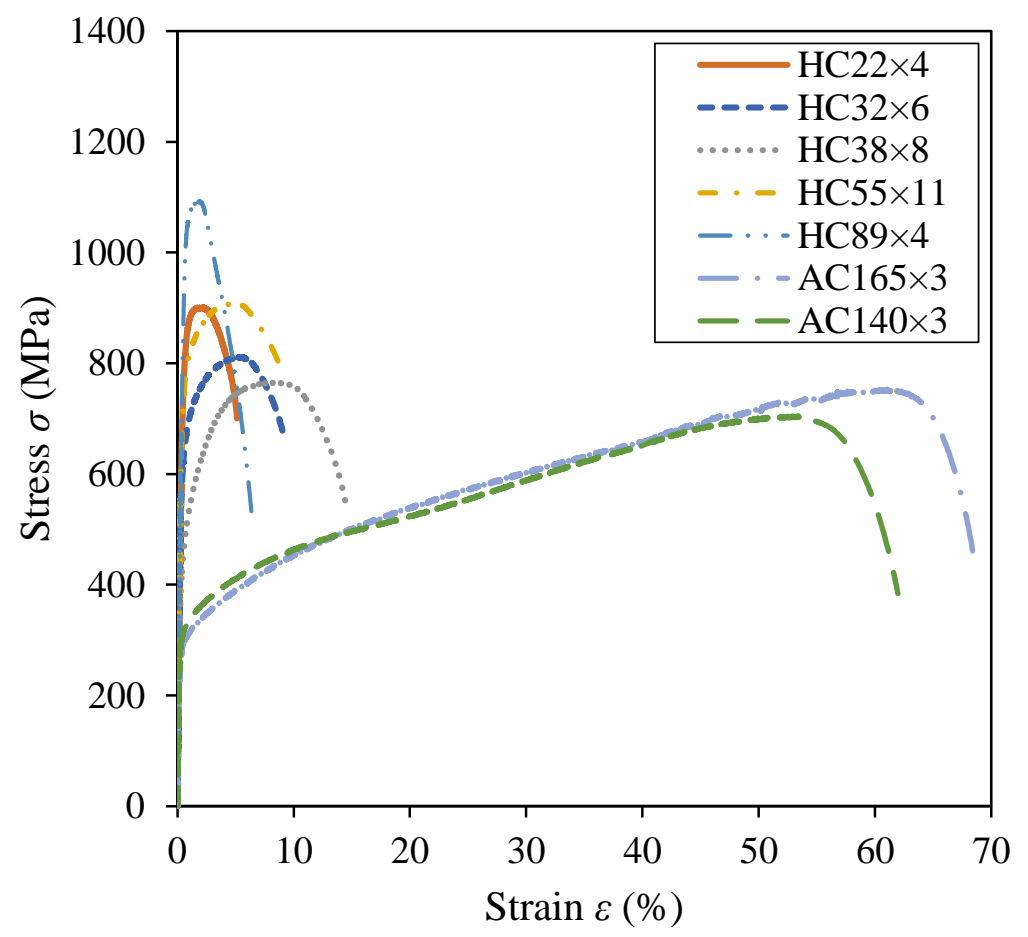

Fig. 4. Full stress-strain curves obtained from tensile coupon tests.

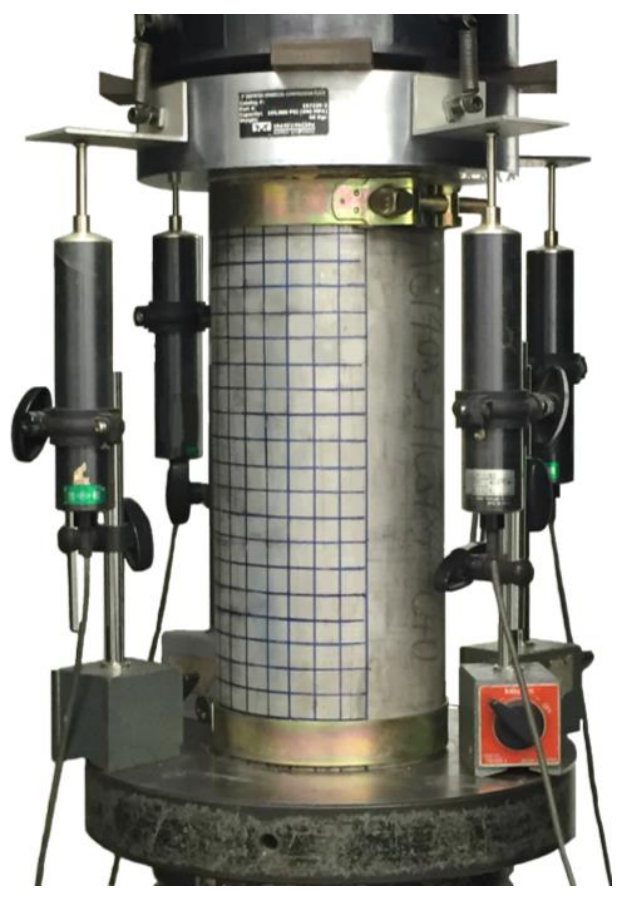

Fig. 5. Typical test set-up of CFDST stub column specimens. 


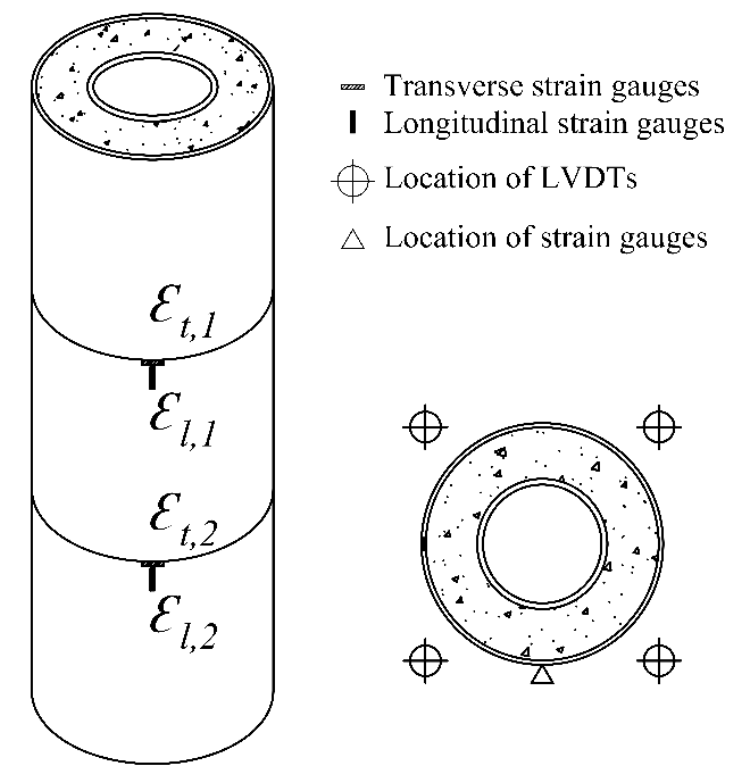

Fig. 6. Arrangements of LVDTs and strain gauges.

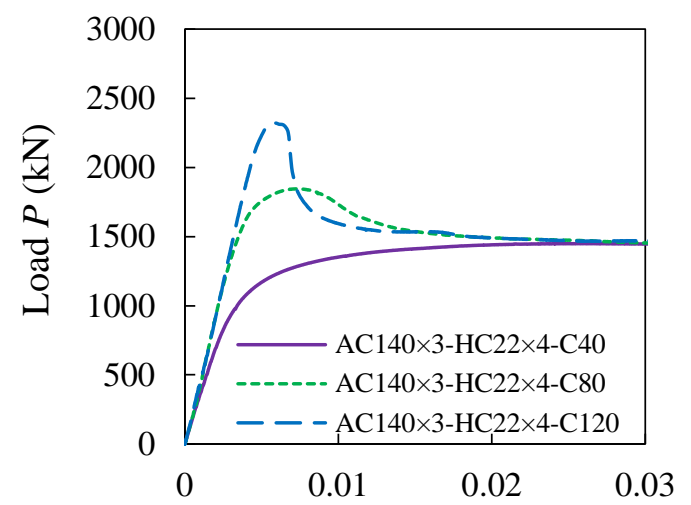

Average axial strain $\varepsilon$

(a) $\mathrm{AC} 140 \times 3-\mathrm{HC} 22 \times 4$

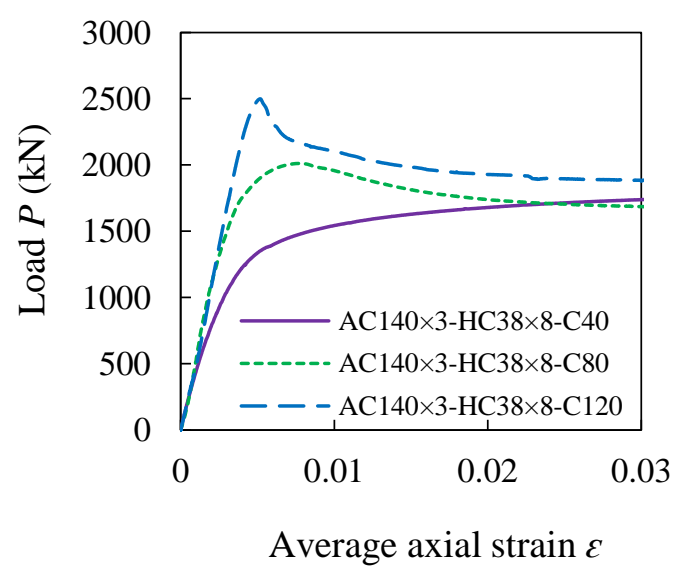

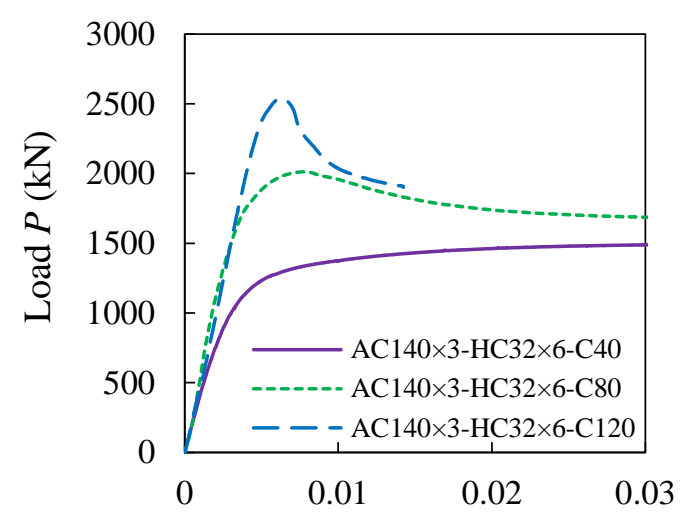

Average axial strain $\mathcal{E}$

(b) $\mathrm{AC} 140 \times 3-\mathrm{HC} 32 \times 6$

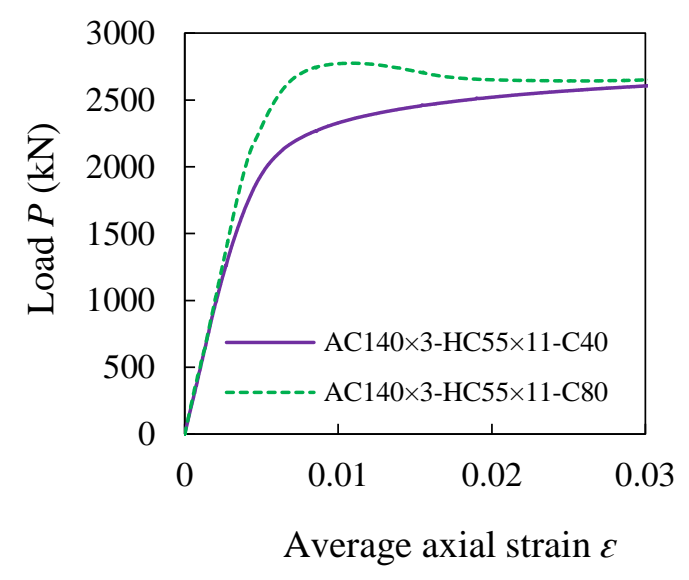

(d) AC140×3-HC55×11 


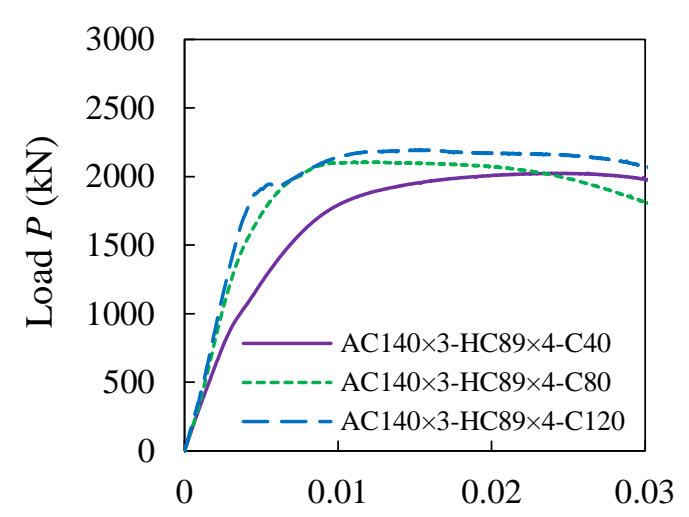

Average axial strain $\varepsilon$

839

840

841

842

843

844

(g) AC165×3-HC32×6

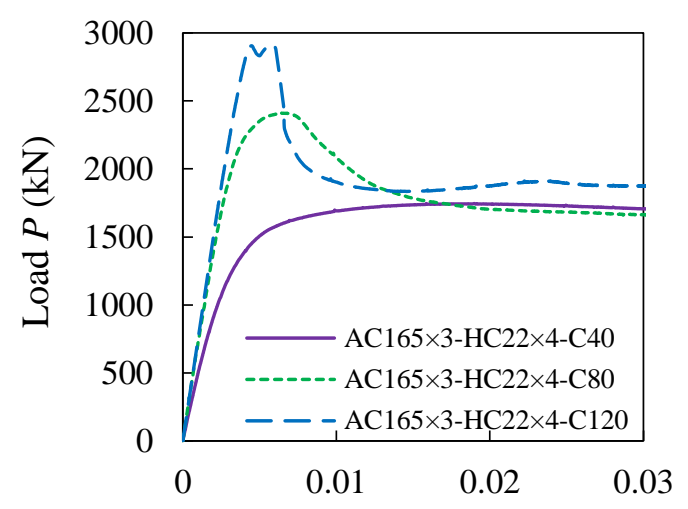

Average axial strain $\mathcal{\varepsilon}$

(f) $\mathrm{AC} 165 \times 3-\mathrm{HC} 22 \times 4$

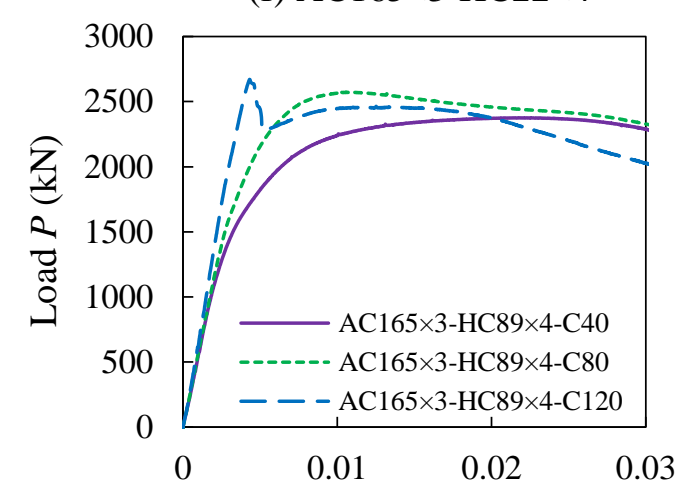

Average axial strain $\varepsilon$

(h) $\mathrm{AC} 165 \times 3-\mathrm{HC} 89 \times 4$

Fig. 7. Load versus average axial strain curves for tested CFDST stub columns.

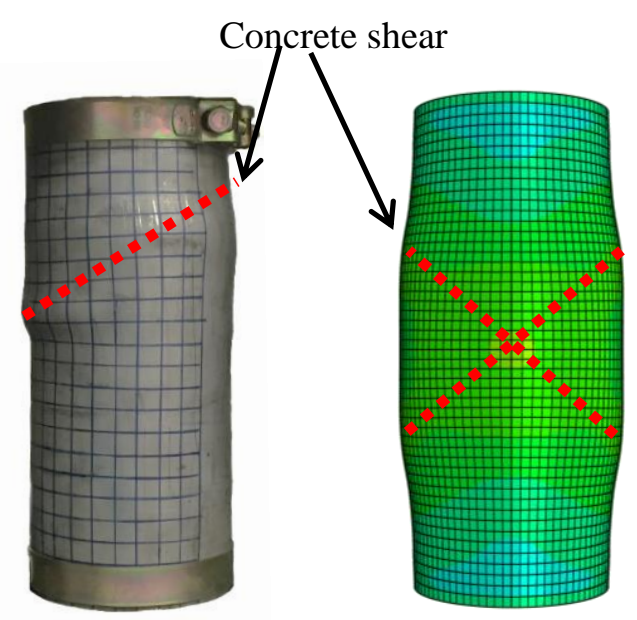

(a) Outward local buckling of outer tube
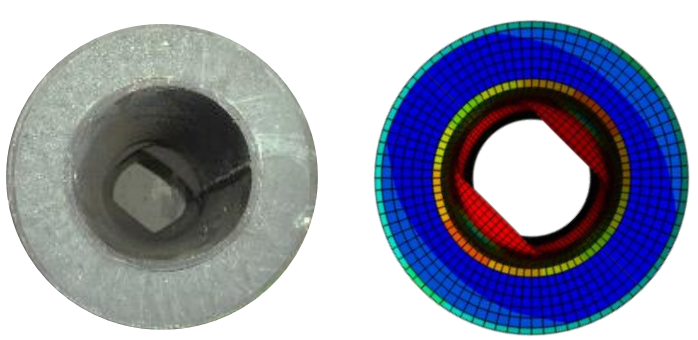

(b) Inward local buckling of inner tube 

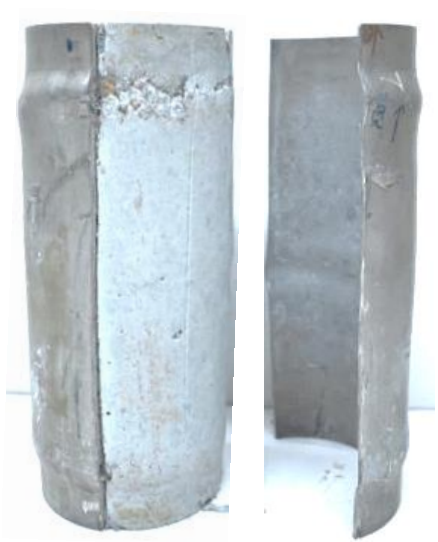

(c) Outward local buckling of outer tube
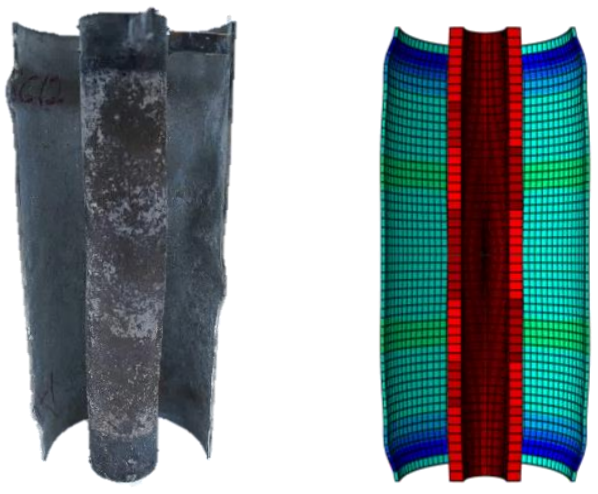

(d) No buckling of inner tube
846

Fig. 8. Comparisons of test and FE failure modes for stub column: (a) and (c) AC140 $\times 3$ HC89×4-C40; (b) and (d) AC140×3-HC55×11-C40.

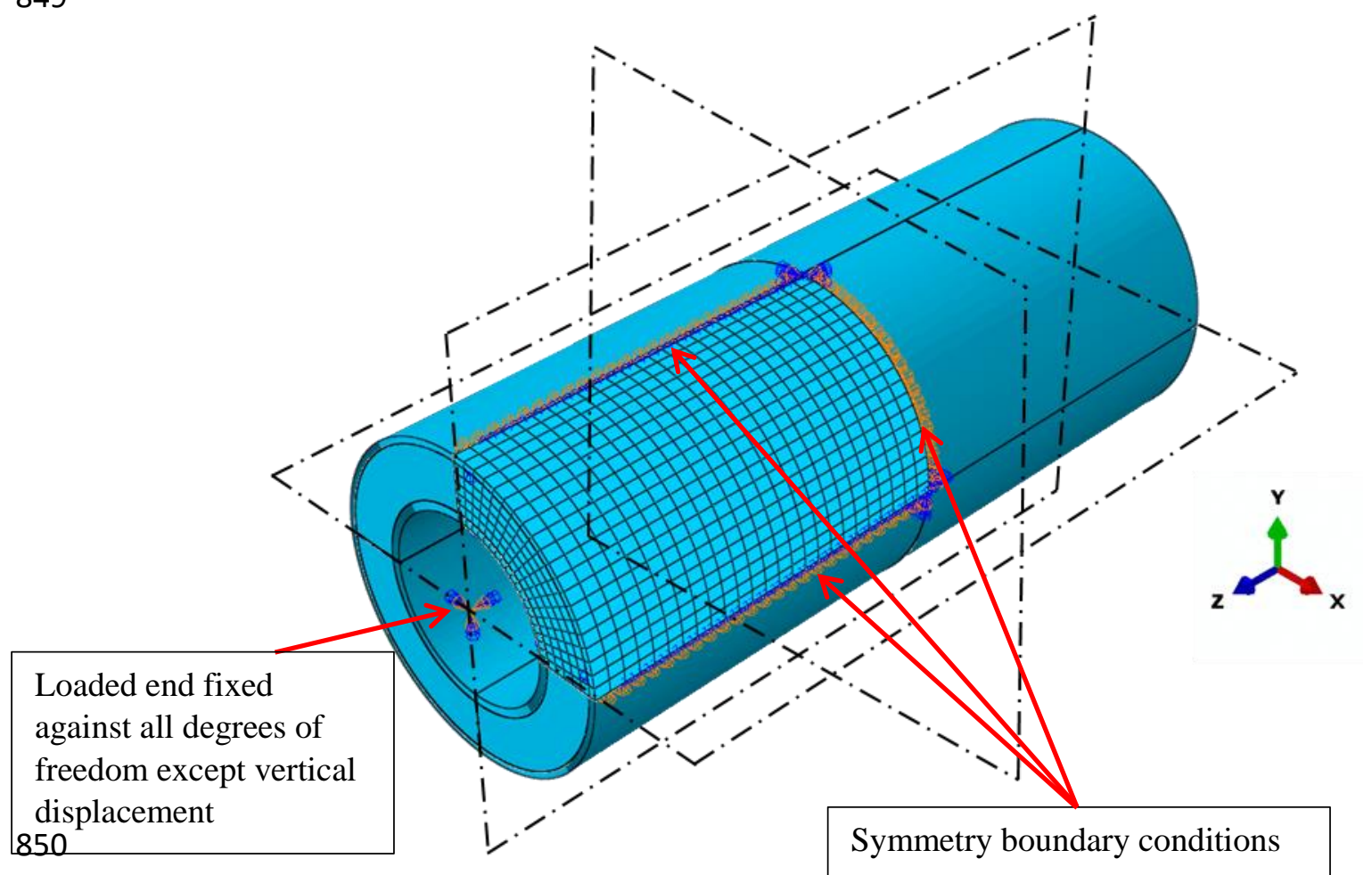


853

854

855

857

858

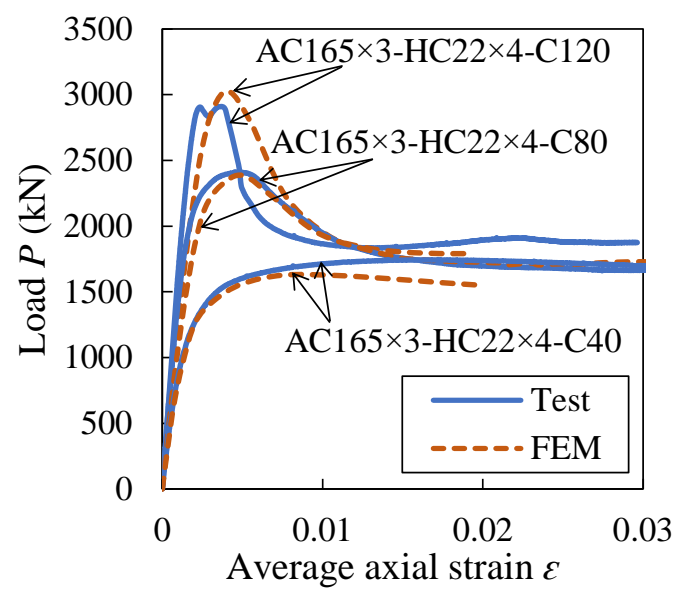

Fig. 10. Comparisons of test and FE load-average axial strain curves.

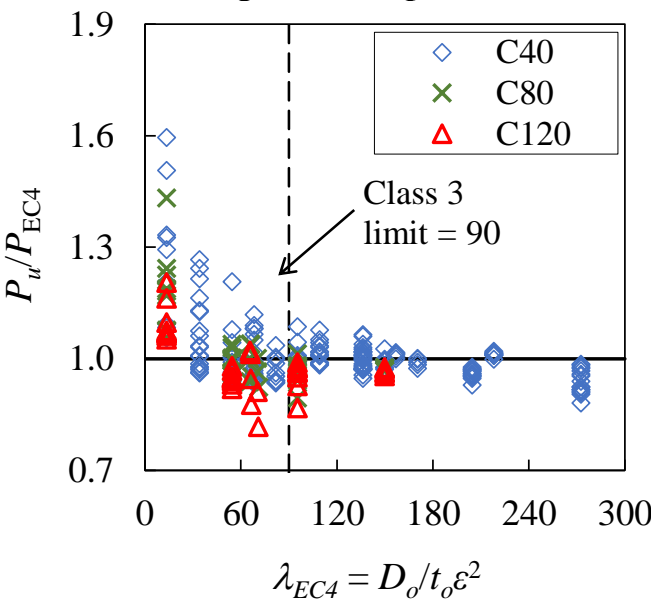

(a) EC4

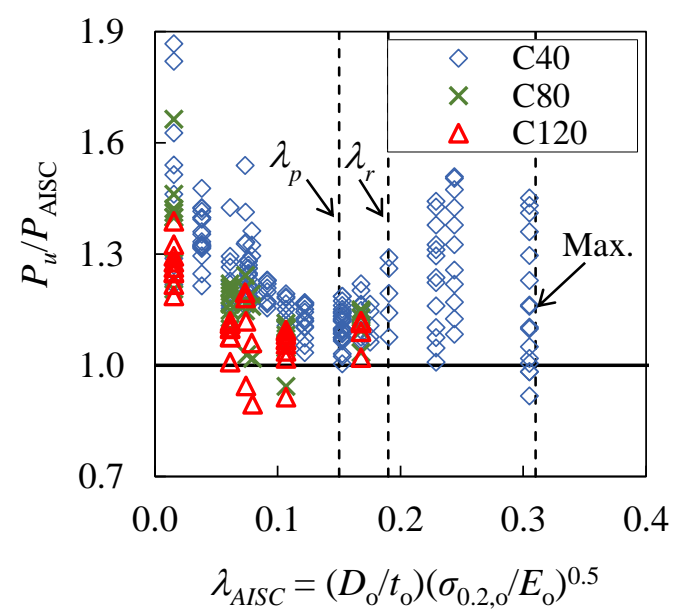

(c) AISC360

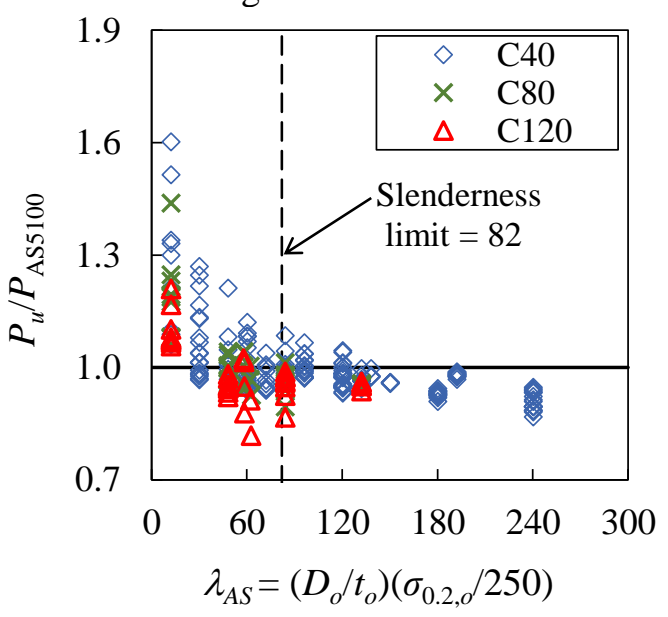

(b) AS 5100

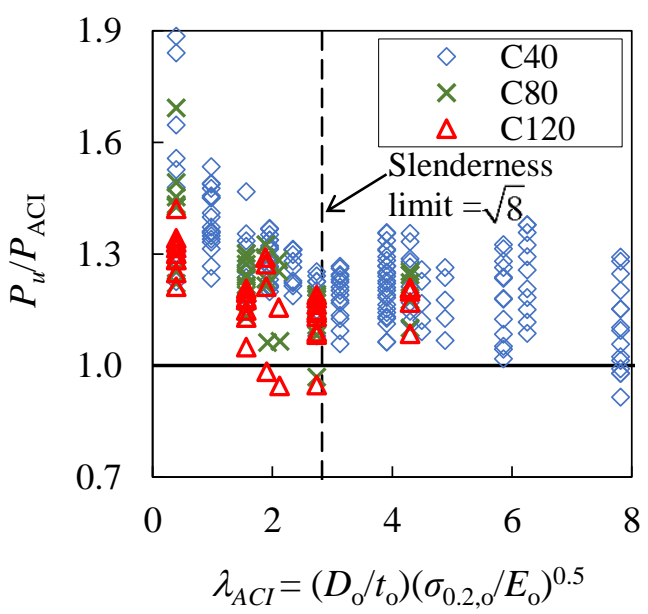

(d) ACI

Fig. 11. Comparisons of test and FE results with strength predictions from design codes. 


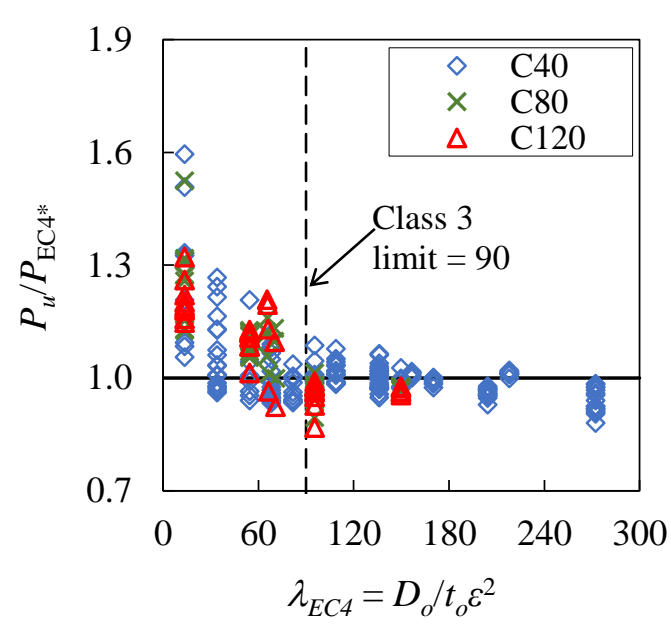

(a) EC4

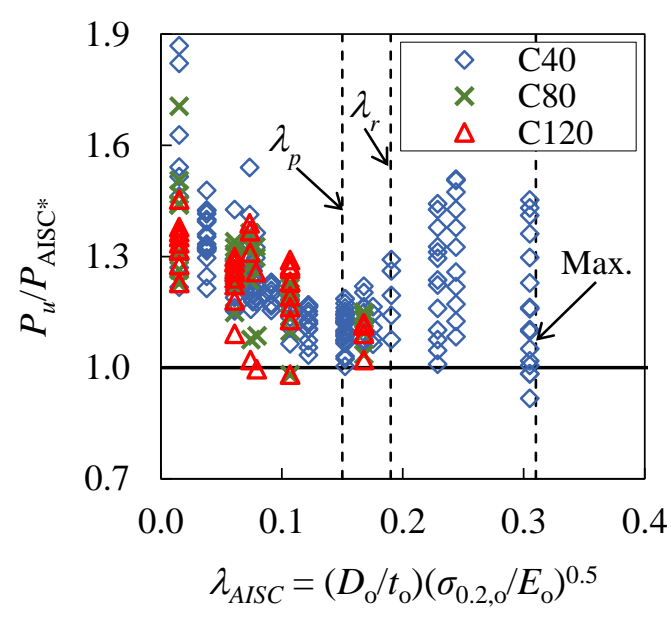

(c) AISC360

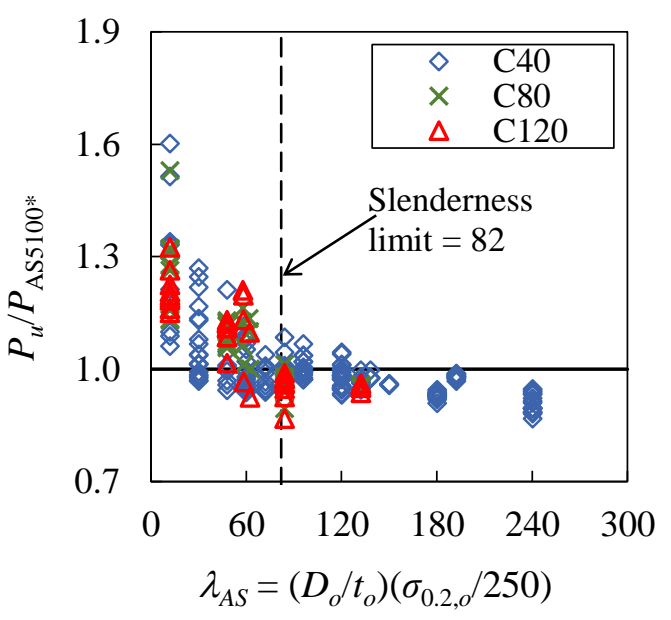

(b) AS 5100

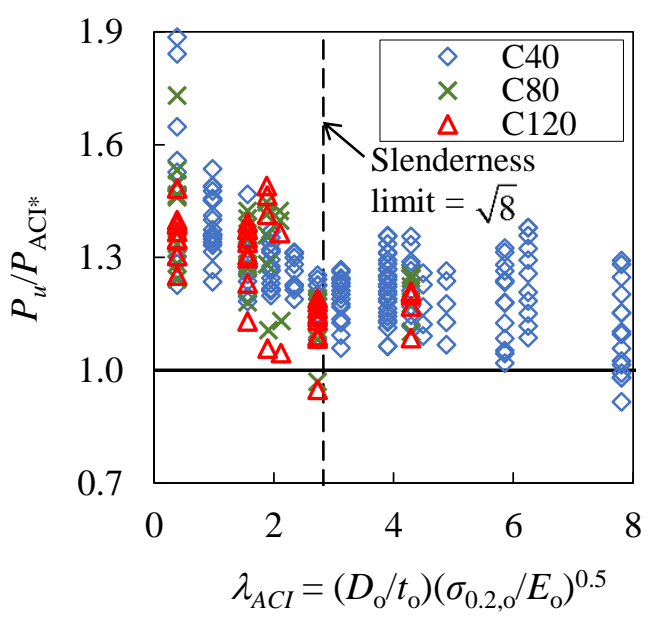

(d) ACI

Fig. 12. Comparisons of test and FE results with modified strength predictions from design codes. 
Table 1 Measured test specimen dimensions.

\begin{tabular}{|c|c|c|c|c|c|c|c|c|c|c|c|c|c|c|c|c|}
\hline \multirow[b]{2}{*}{ Specimen } & \multirow[b]{2}{*}{$\begin{array}{l}\text { Length } \\
L(\mathrm{~mm})\end{array}$} & \multicolumn{3}{|c|}{ Outer tube dimensions } & \multicolumn{3}{|c|}{ Inner tube dimensions } & \multicolumn{3}{|c|}{ Area } & \multicolumn{3}{|c|}{ Material strength } & \multirow[b]{2}{*}{$\begin{array}{c}\text { Ductility } \\
D I\end{array}$} & \multirow{2}{*}{$\begin{array}{c}\text { Test } \\
\text { strength } \\
P_{\text {exp }} \\
(\mathrm{kN}) \\
\end{array}$} & \multirow[b]{2}{*}{$P_{F E} / P_{e x l}$} \\
\hline & & $D_{o}(\mathrm{~mm})$ & $t_{o}(\mathrm{~mm})$ & $D_{o} / t_{o}$ & $D_{i}(\mathrm{~mm})$ & $t_{i}(\mathrm{~mm})$ & $D_{i} / t_{i}$ & $\begin{array}{c}A_{o} \\
\left(\mathrm{~mm}^{2}\right)\end{array}$ & $\begin{array}{c}A_{i} \\
\left(\mathrm{~mm}^{2}\right)\end{array}$ & $\begin{array}{c}A_{c} \\
\left(\mathrm{~mm}^{2}\right)\end{array}$ & $\begin{array}{c}\sigma_{0.2, o} \\
(\mathrm{MPa})\end{array}$ & $\begin{array}{c}\sigma_{0.2, i} \\
(\mathrm{MPa})\end{array}$ & $\begin{array}{c}f_{c} \\
(\mathrm{MPa})\end{array}$ & & & \\
\hline $\mathrm{AC} 140 \times 3-\mathrm{HC} 22 \times 4-\mathrm{C} 40 *$ & 350.0 & 140.2 & 2.92 & 48.0 & 22.1 & 4.09 & 5.4 & 1258 & 231 & 13788 & 300 & 794 & 40.5 & --- & 1410 & 0.97 \\
\hline AC $140 \times 3-\mathrm{HC} 22 \times 4-\mathrm{C} 80$ & 350.0 & 140.2 & 2.91 & 48.2 & 22.1 & 4.10 & 5.4 & 1254 & 231 & 13806 & 300 & 794 & 79.9 & 1.83 & 1845 & 1.02 \\
\hline AC $140 \times 3-\mathrm{HC} 22 \times 4-\mathrm{C} 120$ & 350.0 & 140.2 & 2.89 & 48.5 & 22.1 & 4.08 & 5.4 & 1247 & 230 & 13808 & 300 & 794 & 115.6 & 1.17 & 2321 & 0.99 \\
\hline $\mathrm{AC} 140 \times 3-\mathrm{HC} 32 \times 6-\mathrm{C} 40^{*}$ & 350.0 & 140.3 & 2.89 & 48.5 & 32.0 & 5.48 & 5.8 & 1247 & 456 & 13399 & 300 & 619 & 40.5 & --- & 1423 & 1.05 \\
\hline AC $140 \times 3-\mathrm{HC} 32 \times 6-\mathrm{C} 80$ & 350.0 & 140.2 & 2.92 & 48.0 & 31.9 & 5.27 & 6.1 & 1259 & 440 & 13375 & 300 & 619 & 79.9 & 3.11 & 2012 & 0.96 \\
\hline AC $140 \times 3-H C 32 \times 6-C 120$ & 350.0 & 140.1 & 2.91 & 48.1 & 31.9 & 5.36 & 6.0 & 1253 & 446 & 13362 & 300 & 619 & 115.6 & 1.38 & 2537 & 0.92 \\
\hline $\mathrm{AC} 140 \times 3-\mathrm{HC} 38 \times 8-\mathrm{C} 40^{*}$ & 350.0 & 140.1 & 2.91 & 48.1 & 38.1 & 7.63 & 5.0 & 1255 & 730 & 13028 & 300 & 433 & 40.5 & --- & 1626 & 0.95 \\
\hline AC $140 \times 3-\mathrm{HC} 38 \times 8-\mathrm{C} 80$ & 350.0 & 140.1 & 2.90 & 48.3 & 38.0 & 7.51 & 5.1 & 1250 & 720 & 13034 & 300 & 433 & 79.9 & --- & 2083 & 0.93 \\
\hline AC140×3-HC38×8-C120 & 350.0 & 140.2 & 2.90 & 48.3 & 37.9 & 7.39 & 5.1 & 1249 & 708 & 13052 & 300 & 433 & 115.6 & 1.34 & 2500 & 0.94 \\
\hline AC140×3-HC55×11-C40* & 350.0 & 140.2 & 2.90 & 48.3 & 55.1 & 10.62 & 5.2 & 1253 & 1484 & 11804 & 300 & 739 & 40.5 & --- & 2543 & 0.92 \\
\hline AC140×3-HC55×11-C80 & 350.0 & 140.1 & 2.90 & 48.3 & 55.2 & 10.76 & 5.1 & 1249 & 1503 & 11782 & 300 & 739 & 79.9 & --- & 2775 & 0.96 \\
\hline AC140×3-HC $89 \times 4-C 40$ & 350.0 & 140.1 & 2.87 & 48.8 & 89.0 & 3.89 & 22.9 & 1236 & 1041 & 7962 & 300 & 1029 & 40.5 & 1.42 & 2025 & 0.98 \\
\hline $\mathrm{AC} 140 \times 3-\mathrm{HC} 89 \times 4-\mathrm{C} 80$ & 350.0 & 140.1 & 2.86 & 49.0 & 89.1 & 3.91 & 22.8 & 1233 & 1046 & 7935 & 300 & 1029 & 79.9 & 2.77 & 2107 & 0.97 \\
\hline $\mathrm{AC} 140 \times 3-\mathrm{HC} 89 \times 4-\mathrm{C} 120$ & 350.0 & 140.2 & 2.88 & 48.7 & 89.1 & 3.91 & 22.8 & 1244 & 1046 & 7963 & 300 & 1029 & 115.6 & 2.22 & 2195 & 1.04 \\
\hline $\mathrm{AC} 165 \times 3-\mathrm{HC} 22 \times 4-\mathrm{C} 40$ & 413.0 & 165.3 & 2.94 & 56.2 & 22.0 & 4.14 & 5.3 & 1499 & 233 & 19568 & 276 & 794 & 40.5 & $\begin{array}{ll}-- \\
--\end{array}$ & 1750 & 0.93 \\
\hline $\mathrm{AC} 165 \times 3-\mathrm{HC} 22 \times 4-\mathrm{C} 80$ & 413.0 & 165.2 & 2.94 & 56.3 & 22.1 & 4.09 & 5.4 & 1497 & 231 & 19566 & 276 & 794 & 79.9 & 1.63 & 2413 & 0.99 \\
\hline AC165×3-HC22×4-C120 & 413.0 & 165.3 & 2.94 & 56.3 & 22.1 & 4.04 & 5.5 & 1498 & 229 & 19583 & 276 & 794 & 115.6 & 1.18 & 2911 & 1.04 \\
\hline AC $165 \times 3-\mathrm{HC} 32 \times 6-\mathrm{C} 40$ & 413.0 & 165.3 & 2.93 & 56.4 & 31.9 & 5.35 & 6.0 & 1496 & 446 & 19158 & 276 & 619 & 40.5 & --- & 1943 & 0.88 \\
\hline AC $165 \times 3-\mathrm{HC} 32 \times 6-\mathrm{C} 40 \mathrm{R}$ & 413.0 & 165.3 & 2.94 & 56.2 & 31.9 & 5.39 & 5.9 & 1501 & 448 & 19162 & 276 & 619 & 40.5 & --- & 1891 & 0.91 \\
\hline $\mathrm{AC} 165 \times 3-\mathrm{HC} 32 \times 6-\mathrm{C} 80$ & 413.0 & 165.3 & 2.94 & 56.1 & 31.8 & 5.25 & 6.1 & 1501 & 438 & 19154 & 276 & 619 & 79.9 & 2.76 & 2550 & 0.96 \\
\hline $\mathrm{AC} 165 \times 3-\mathrm{HC} 89 \times 4-\mathrm{C} 40$ & 413.0 & 165.5 & 2.92 & 56.7 & 89.0 & 3.92 & 22.7 & 1491 & 1048 & 13786 & 276 & 1029 & 40.5 & 1.74 & 2375 & 0.96 \\
\hline AC165×3-HC $89 \times 4-C 80$ & 413.0 & 165.4 & 2.91 & 56.9 & 89.1 & 3.91 & 22.8 & 1485 & 1046 & 13770 & 276 & 1029 & 79.9 & 3.46 & 2580 & 1.01 \\
\hline $\mathrm{AC} 165 \times 3-\mathrm{HC} 89 \times 4-\mathrm{C} 120$ & 413.0 & 165.2 & 2.92 & 56.7 & 88.9 & 3.88 & 22.9 & 1487 & 1036 & 13744 & 276 & 1029 & 115.6 & 5.34 & 2671 & 1.12 \\
\hline Mean & & & & & & & & & & & & & & & & 0.97 \\
\hline Cov & & & & & & & & & & & & & & & & 0.055 \\
\hline
\end{tabular}

Note: * The peak loads were not obtained for these specimens. 
Table 2 Measured material properties obtained from tensile coupon tests.

\begin{tabular}{cccccccc}
\hline Section & $\begin{array}{c}\sigma_{0.2} \\
(\mathrm{MPa})\end{array}$ & $\begin{array}{c}\sigma_{u} \\
(\mathrm{MPa})\end{array}$ & $\begin{array}{c}E \\
(\mathrm{GPa})\end{array}$ & $\begin{array}{c}\varepsilon_{f} \\
(\%)\end{array}$ & $n$ & $m$ & $\sigma_{u} / \sigma_{0.2}$ \\
\hline $\mathrm{AC} 140 \times 3 *$ & 300 & 705 & 197 & 62 & 5.3 & 2.5 & 2.4 \\
$\mathrm{AC} 165 \times 3$ & 276 & 753 & 200 & 68 & 4.4 & 2.3 & 2.7 \\
$\mathrm{HC} 22 \times 4$ & 794 & 901 & 197 & 5 & 5.8 & 4.1 & 1.1 \\
$\mathrm{HC} 32 \times 6$ & 619 & 811 & 208 & 9 & 5.4 & 3.7 & 1.3 \\
HC38 $\times 8^{*}$ & 433 & 765 & 197 & 15 & 6.2 & 3.0 & 1.8 \\
$\mathrm{HC} 55 \times 11^{*}$ & 739 & 941 & 211 & 9 & 8.4 & 3.7 & 1.3 \\
$\mathrm{HC} 89 \times 4^{*}$ & 1029 & 1093 & 209 & 6 & 5.7 & 4.3 & 1.1 \\
\hline
\end{tabular}

875

876

877

878

879

880

881

882

883

884

\begin{tabular}{cccccc}
\hline \multicolumn{2}{c}{ No. of tests: 23} & EC4 & AS 5100 & AISC 360 & ACI 318 \\
No. of FE simulations: 239 & Mean & 1.01 & 1.00 & 1.20 & 1.24 \\
\multirow{2}{*}{$P_{u} / P_{\text {code }}$} & COV & 0.091 & 0.097 & 0.119 & 0.106 \\
\hline
\end{tabular}

Note: * Measured material properties employed in parametric studies.

Table 3 Concrete mix design.

\begin{tabular}{ccccccc}
\hline Nominal concrete & \multicolumn{5}{c}{ Mix proportions (relative to the weight of cement) } \\
\cline { 2 - 7 } strength (MPa) & Cement & Water & Fine aggregate & $10 \mathrm{~mm}$ aggregate & $\mathrm{CSF}^{\mathrm{a}}$ & $\mathrm{SP}^{\mathrm{b}}$ \\
\hline C40 & 1 & 0.56 & 1.67 & 2.51 & 0 & 0.004 \\
$\mathrm{C} 80$ & 1 & 0.32 & 1.25 & 1.88 & 0 & 0.02 \\
C120 & 1 & 0.21 & 1.02 & 1.53 & 0.09 & 0.053 \\
\hline
\end{tabular}

Note: ${ }^{\mathrm{a}} \mathrm{CSF}=$ Condensed silica fume; ${ }^{\mathrm{b}} \mathrm{SP}=$ Super plasticizer

Table 4 Measured concrete cylinder strengths.

\begin{tabular}{ccccccc}
\hline & $\begin{array}{c}\text { Mean value } \\
\text { of } \\
\text { concrete } \\
\text { Strength } \\
28-\text { day } \\
\text { (MPa) }\end{array}$ & $\begin{array}{c}\text { Coefficient } \\
\text { of } \\
\text { variation } \\
(\mathrm{COV})\end{array}$ & $\begin{array}{c}\text { Number } \\
\text { of } \\
\text { concrete } \\
\text { cylinder } \\
\text { tests }\end{array}$ & $\begin{array}{c}\text { Mean value } \\
\text { of } \\
\text { concrete } \\
\text { strength at } \\
\text { days of } \\
\text { column tests } \\
\text { (MPa) }\end{array}$ & $\begin{array}{c}\text { Coefficient } \\
\text { of } \\
\text { variation } \\
\text { (COV) }\end{array}$ & $\begin{array}{c}\text { Number } \\
\text { of } \\
\text { concrete } \\
\text { cylinder } \\
\text { tests }\end{array}$ \\
\hline C40 & 36.2 & 0.031 & 4 & 40.5 & 0.026 & 5 \\
C80 & 77.6 & 0.028 & 4 & 79.9 & 0.040 & 7 \\
C120 & 108.2 & 0.080 & 4 & 115.6 & 0.025 & 6 \\
\hline
\end{tabular}

Table 5 Ranges of variation of parameters for the parametric study.

\begin{tabular}{cccccc}
\hline \multirow{2}{*}{ Parameter } & & $D_{o} / t_{o}$ & $D_{i} / t_{i}$ & $\begin{array}{c}f_{c} \\
(\mathrm{MPa})\end{array}$ & $\begin{array}{c}\sigma_{0.2, i} \\
(\mathrm{MPa})\end{array}$ \\
\hline \multirow{2}{*}{ Range } & Max. & 200 & 150 & 120 & 1029 \\
& Min. & 10 & 8 & 40 & 433 \\
\hline
\end{tabular}

Table 6 Overall comparison of stub column test and FE results with predicted strengths. 
Table 7 Code limits on cross-sectional slendernesses and material strengths.

\begin{tabular}{ccccc}
\hline \multirow{2}{*}{ Design codes } & \multicolumn{2}{c}{ Limits on cross-sectional slenderness } & \multicolumn{2}{c}{$\begin{array}{c}\text { Limits on material } \\
\text { strengths }\end{array}$} \\
\cline { 2 - 5 } EN 1994-1-1 & $D_{o} / t_{o} \leq 90 \frac{235}{\sigma_{0.2, o}} \frac{E_{o}}{210000}$ & $\begin{array}{c}\text { Normalised slenderness } \\
\text { limit }\end{array}$ & $\begin{array}{c}\sigma_{0.2} \\
(\mathrm{MPa})\end{array}$ & $\begin{array}{c}f_{c} \\
(\mathrm{MPa})\end{array}$ \\
\hline AS 5100 & $\lambda_{e}=\frac{D_{o}}{t_{o}} \frac{\sigma_{0.2, o}}{235} \leq 82$ & $\left.\frac{210000}{E_{o}} \frac{\sigma_{0.2, o}}{235}\right) \leq 90$ & $235-460$ & $20-50$ \\
AISC 360 & $\lambda_{p}=\frac{D_{o}}{t_{o}} \leq 0.31 \frac{\sigma_{0.2, o}}{235} \leq 82$ & $230-400$ & $25-65$ \\
ACI 318 & $t_{o} \geq D_{o} \sqrt{\frac{\sigma_{0.2, o}}{8 E_{o}}}$ & $\frac{D_{o}}{t_{o}} \frac{\sigma_{0.2, o}}{E_{o}} \leq 0.31$ & $\leq 525$ & $21-70$ \\
\hline
\end{tabular}

Table 8. Limiting $D_{o} / t_{o}$ in composite members under axial compression in AISC360.

\begin{tabular}{ccc}
\hline $\begin{array}{c}\text { Compact/noncompact } \\
\lambda_{p}\end{array}$ & $\begin{array}{c}\text { Noncompact/slender } \\
\lambda_{r}\end{array}$ & Maximum \\
\hline $0.15 E_{o} / \sigma_{0.2, o}$ & $0.19 E_{o} / \sigma_{0.2, o}$ & $0.31 E_{o} / \sigma_{0.2, o}$ \\
\hline
\end{tabular}

Table 9. Average ratios of test-to-design predictions for each concrete grade.

\begin{tabular}{|c|c|c|c|c|c|c|c|c|c|}
\hline \multirow{2}{*}{\multicolumn{2}{|c|}{$\begin{array}{c}\text { Concrete } \\
\text { grade }\end{array}$}} & \multicolumn{8}{|c|}{ Ratio of test-to-predicted strengths } \\
\hline & & $P_{u} / P_{\mathrm{EC} 4}$ & $P_{u} / P_{\mathrm{EC} 4 *}$ & $P_{u} / P_{\mathrm{AS} 5100}$ & $P_{u} / P_{\mathrm{AS} 5100^{*}}$ & $P_{u} / P_{\mathrm{AISC}}$ & $P_{u} / P_{\mathrm{AISC}^{*}}$ & $P_{u} / P_{\mathrm{ACI}}$ & $P_{u} / P_{\mathrm{ACI}^{*}}$ \\
\hline \multirow{2}{*}{$\mathrm{C} 40$} & Mean & 1.08 & 1.08 & 1.08 & 1.08 & 1.29 & 1.29 & 1.33 & 1.33 \\
\hline & $\mathrm{COV}$ & 0.114 & 0.114 & 0.118 & 0.118 & 0.126 & 0.126 & 0.113 & 0.113 \\
\hline \multirow{2}{*}{$\mathrm{C} 80$} & Mean & 1.02 & 1.09 & 1.02 & 1.09 & 1.18 & 1.23 & 1.24 & 1.27 \\
\hline & $\mathrm{COV}$ & 0.103 & 0.118 & 0.106 & 0.122 & 0.118 & 0.127 & 0.107 & 0.117 \\
\hline \multirow{2}{*}{$\mathrm{C} 120$} & Mean & 0.98 & 1.07 & 0.98 & 1.07 & 1.12 & 1.19 & 1.18 & 1.23 \\
\hline & $\mathrm{COV}$ & 0.078 & 0.105 & 0.080 & 0.108 & 0.097 & 0.115 & 0.087 & 0.107 \\
\hline
\end{tabular}

890

891

Table 10. Reliability analysis results calculated according to EN 1990.

\begin{tabular}{ccccccc}
\hline Design code & Sample type & Sample number & $k_{\mathrm{d}, \mathrm{n}}$ & $b$ & $V_{\delta}$ & $\gamma_{\mathrm{M} 0}$ \\
\hline EC4 & Test+FE & 262 & 3.128 & 1.01 & 0.083 & 0.99 \\
EC4 $*$ & Test+FE & 262 & 3.128 & 1.03 & 0.093 & 0.97 \\
\hline
\end{tabular}

